\title{
دور معلمي الاجتماعيات في تنمية قيم المواطنة لدى طلبة المرحلة الثانوية في محافظة الأحمدي بلدولة الكويت من وجهة نظر الطلبة
}

\section{ملوح باجي الخريشا}

أستاذ دكتور في قسم الأصهول والإدارة التربوية- جامعاة مؤتة- الأردن

malkhrisha1@yahoo.com

\author{
علي حضيرم الهاجري \\ وزارة التربية- قسم الدراسات الاجتماعية- الكويت \\ alialhajry1992@gmail.com
}

DOI: https://doi.org/DOI:10.31559/EPS2020.8.2.8

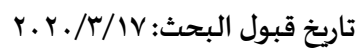

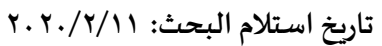

هدفت الدراسة إلى التعرف على دور معلمي الاجتماعيات في تنمية قيم المواطنة لدى طلبة المرحلة الثانوية في محافظة الأحمدي بدولة الكويت من وجهة نظر الطلبة. وتكونت عينة الدِّراسة من (7ع ه) طالباً وطالبة، تم اختيارهم بالطريقة الطبقية العشـوائية. ولتحقيق أهداف الدراسة تم تطوير

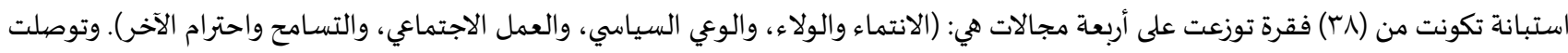

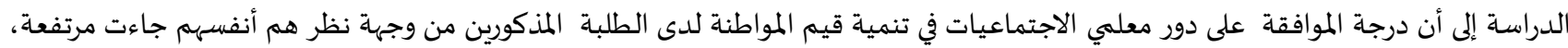

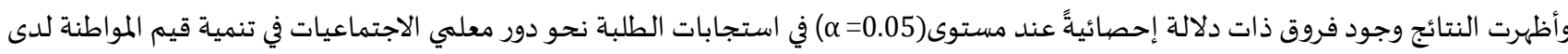

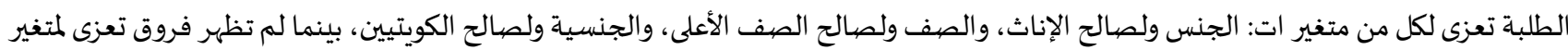
التخصص. وفي ضوء النتائج يوصي الباحثان بعدة توصيات منها: ضرورة قيام المعلمون بتدريب الطلبة على تحمل المسؤولية من خلال تكليفهم بالواجبات، وإشراك جميع الطلبة الكويتين وغيرهم في جميع الأنشطة والفعاليات التي تعزز قيم المواطنة. الكلمات المفتاحية: معلم الاجتماعيات؛ قيم المواطنة؛ الطلبة؛ دولة الكويت.

\section{(ㄷ) (1)}

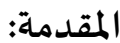

يشهد العالم منذ منتصف القرن المنصرم تقدماً سريعاً في مجالات العلوم والتكنولوجيا وما رافقه من تطور متسارع في وسائل الأعلام،

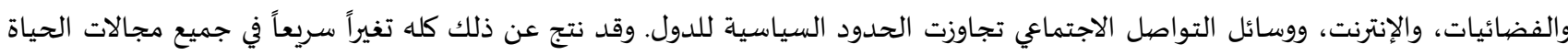

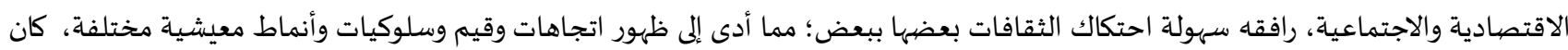

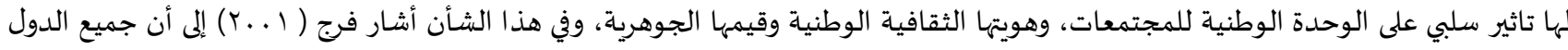

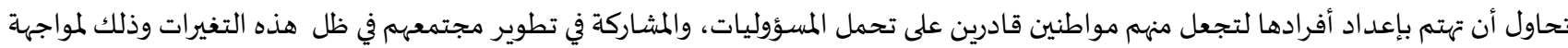
الإحساس بالأغتراب، وضعف الأحساس بالهوية والأنتماء، وقلة المشاركة السياسية.

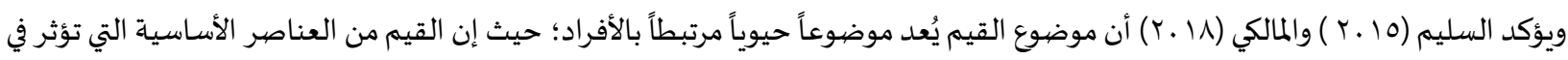
سلوكهم، واتجاهاتهم، وعلاقاتهم مع مجتمعهم: فالقيم تلعب دوراً مهمًا في تدعيم الأنظمة الاجتماعية في المجتمع، وهي التي تؤدي إلى التماسك الاجتماعي

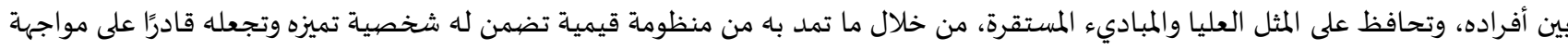

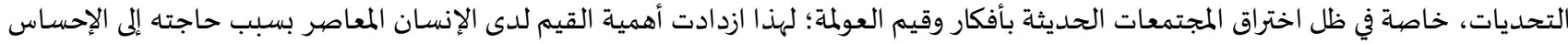


بثقافته وهويته وانتمائه لوطنه، كما تنوعت القيم، ومنها: الدينية، والاجتماعياة، والأخلاقية، والوطنية، والمهنية، والعلمياة.

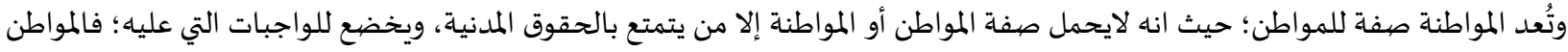
في الدولة هو الذي يشارك في مسيرة الحكم في بلاده، ويعمل للرقي بمجتمعها في حدود ماله وما عليه، إذ أن المواطن له ثلاثة أركان يجب أن أن تتوفر وهي:

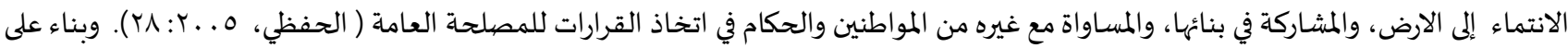
ذلك يمكن القول أن المواطنة هي فكرة جامعة تضهم جميع المكونات الدينية والعرقية والقبلية والطائفية التي يشملها ذلك المجتمع، وهي بمثابة الرابط

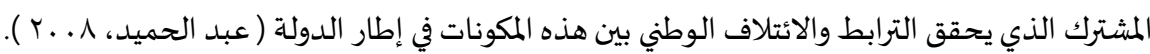
وقد أصبحت قيم المواطنة من المواضيع المهمة في تنمية البشرية وتطويرها، وهي من الأبعاد الأساسية لهذا الأمر. ويعد ازدياد الشعور بالمواطنة من

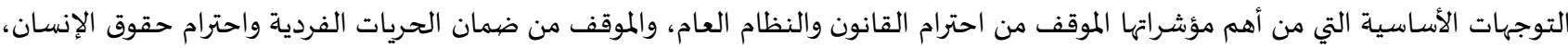

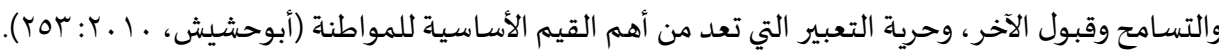

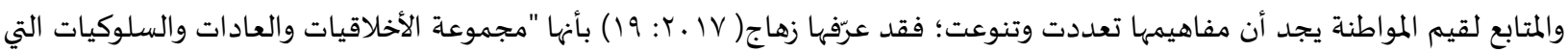

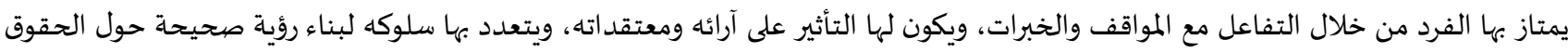

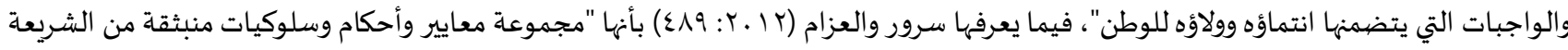

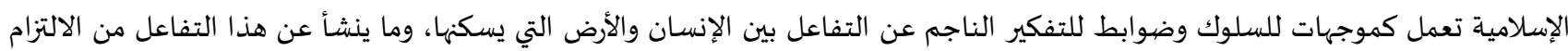
بالحقوق والواجبات في شتى مناحي الحياة وترجمة ذلك إلى سلوكيات وصولاً إلى تكوين الإنسان الصالح وإقامة المجتمع المسلمانم.

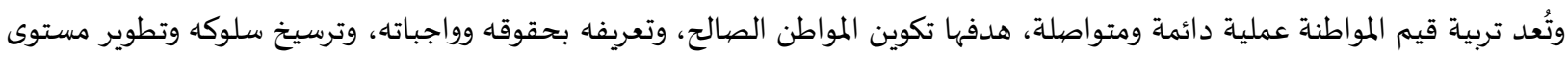

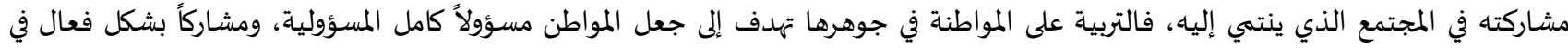

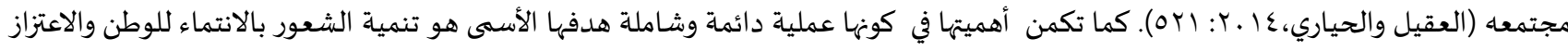

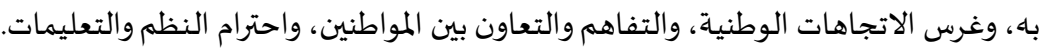

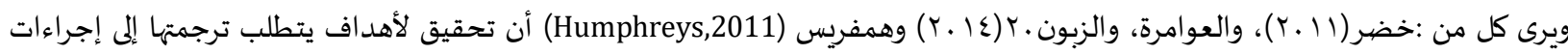

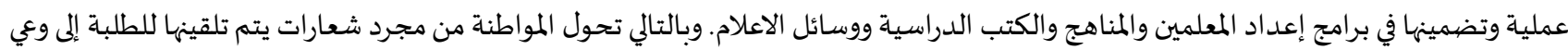

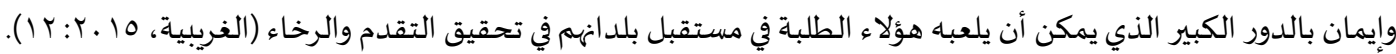

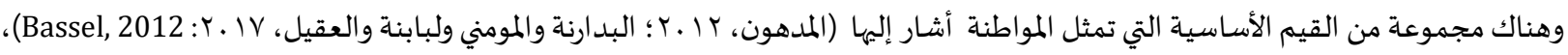
ا. الانتماء والولاء الوطني: حاجة أساسية في أعماق الفرد، ينبني التأكيد عليها والاهتمام بغرسها وترسيخها في نفوسهم لتأكيد وفائهم وولائهم

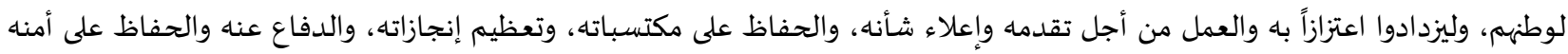

$$
\text { واستقراره. }
$$

r. الوعي السياسي: معرفة الطلبة للواقع السياسي والاجتماعي والتنظيمات السياسية والأحداث الجارية على المستوى المحلي والعالمي، وإدراكهم لحقوقهم وواجباتهم السياسيةة؛ بما يدفعهم للتأثير والمشاركة الفعالة في الحياة السياسية لمجتمعهيم.

r. المشاركة المجتمعية: تعمل على تنظيم جهود الأفراد والجماعات والأجهزة الرسمية وغير الرسمية في المجتمع؛ عبر التنسيق والتكامل فيما بينها

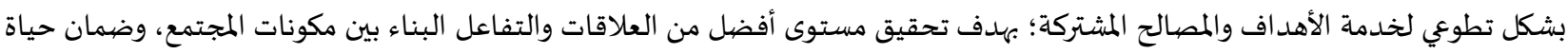

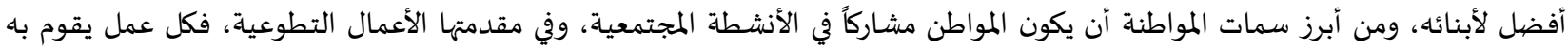

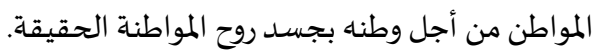

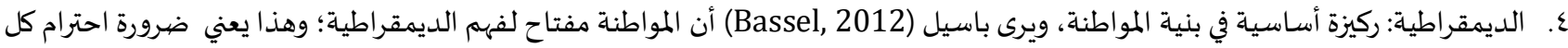

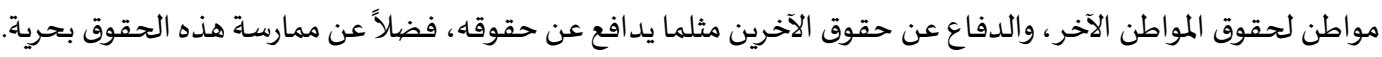

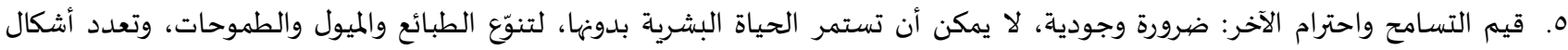

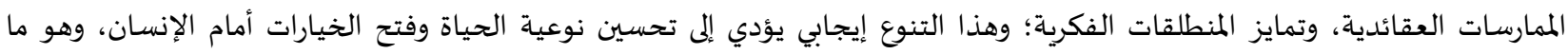

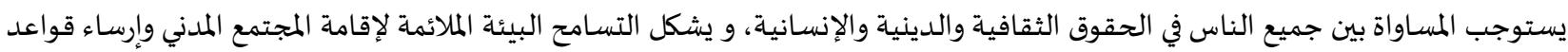
التعدّدية وقبول الاختلاف في الرأي والفكر واحترام سيادة المباد القانون.

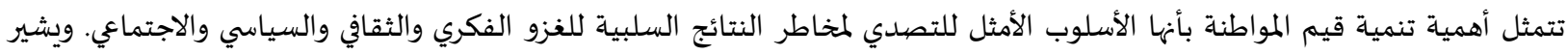

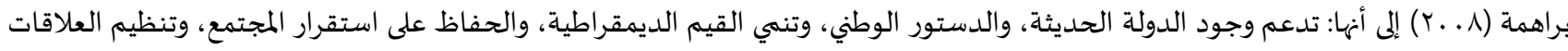

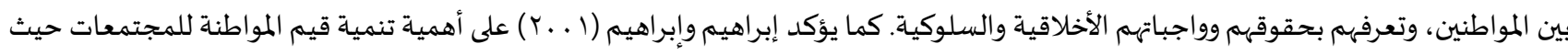

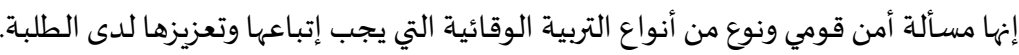


وفي هذا المجال يرى طه وعبد الحكيم (r ا ـr) بأن تنمية قيم المواطنة لدى الطلبة هي الأساس في مواجهة التحديات الحاضرة والمستقبلية التي

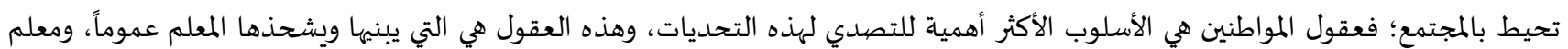

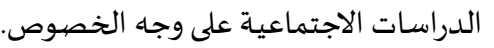
وعلى الرغم من إرتباط قيم المواطنة بعدد من المواد الدراسية، فإن مادة الاجتماعيات من أكثر المواد المدرسية أهمية فيما يتعلق بتنشئة المواطن

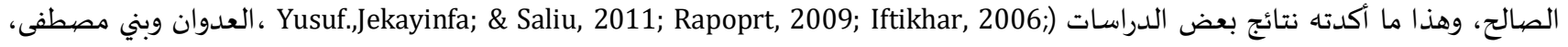

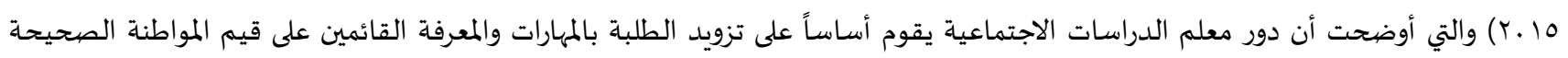

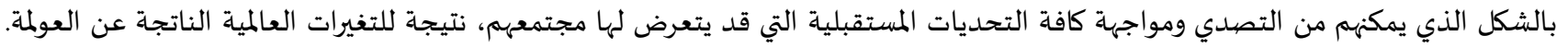

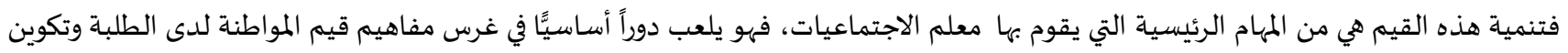

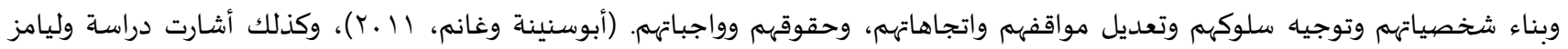
(Williams, 2002) الصف، ليكون قدوتهم في سلوكه.

مشكلة الدراسة وأسئلتها:

يُعد بناء الإنسان المواطن الصالح من أهم الأهداف التي يجب أن تعمل على تحقيقها كل المؤسسات التربوية وخاصية المدرسة. وقد أكدت بعض

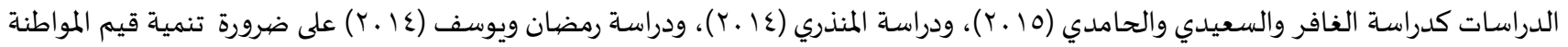

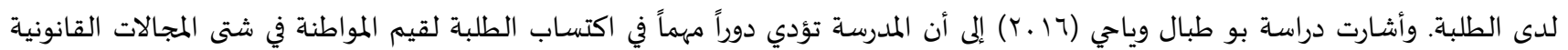

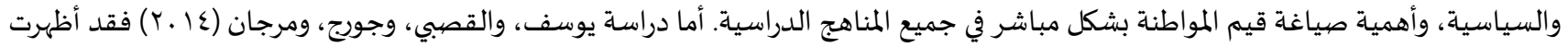

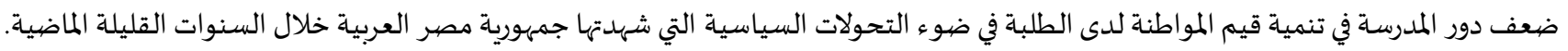

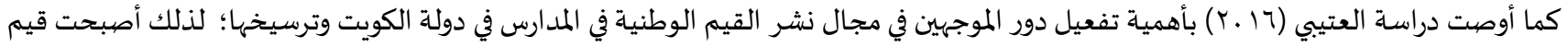

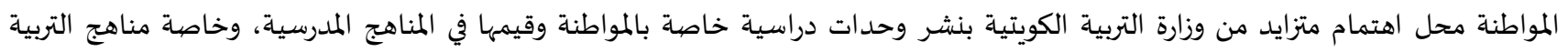

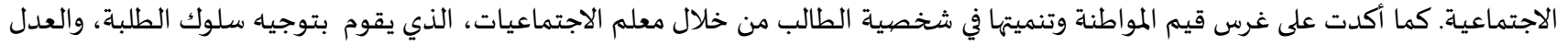

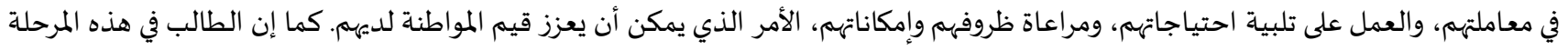

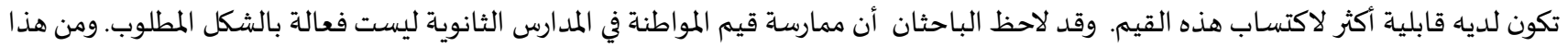

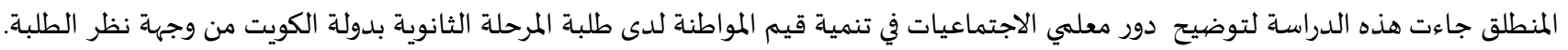

وقد سعت هذه الدراسة للاجابة عن الاسئلة التالية:

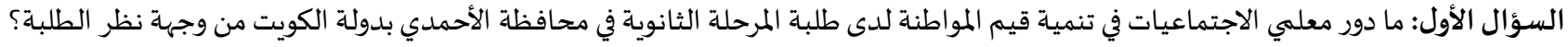

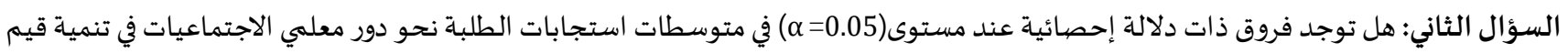

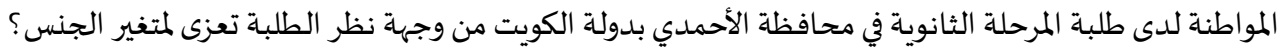

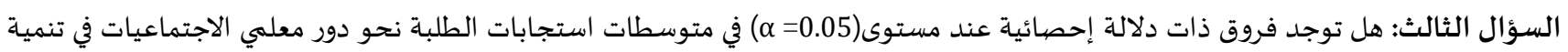

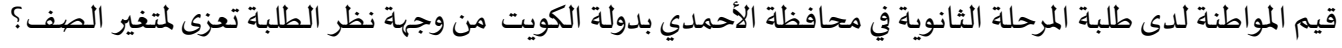

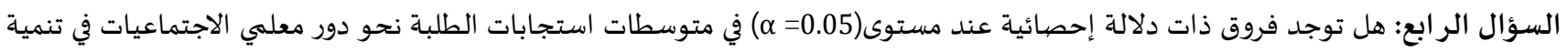

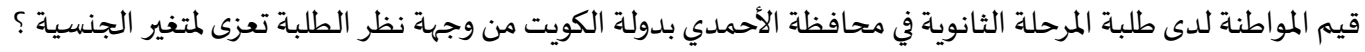

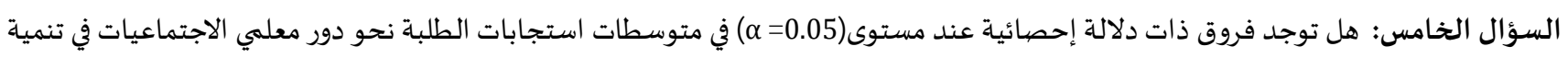

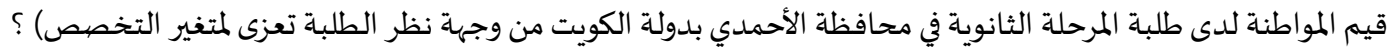

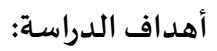

هدفت هذه الدراسة إلى تحقيق ما يلي:

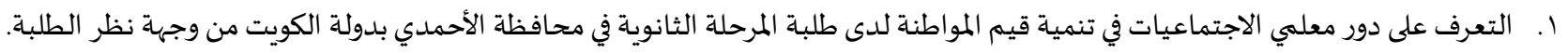
r. بيان اثر متغيرات الدراسة ( الجنس، والصف، والجنسية، والتخصص) على دور معلهي الاجتماعيات في تنمية قيم المواطنة لدى طلبة المرحلة 
تتمثل أهمية هذه الدراسة النظرية والعملية من خلال الآتي: 1. تكمن الأهمية النظرية لهذه الدراسة في حداثة موضوعها، والحاجة للبحث فيها.

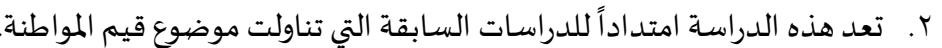
م. قد تثير هذه الدراسة الرغبة لدى الباحثين لإجراء دراسات وأبحاث تتعلق بموضوع قيم المواطنة في مراحل دراسية أخرى وفي مناطق مختلفة،

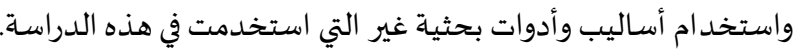

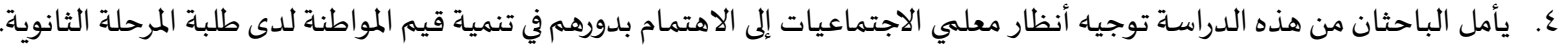

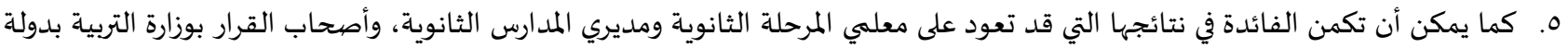
الكويت وهي إمكانية تعزيز قيم المواطنة في المدارس.

7 ا ق قد يستفيد من النتائج القائمين على تطوير المناهج والبرامج التدريبية التي تزيد من مهارات المعلمين في مجال تنمية قيم المواطنة.

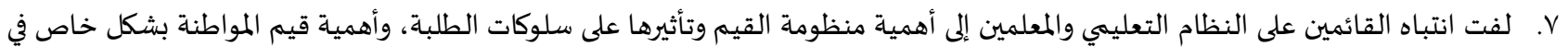
بناء شخصية طالب المرحلة الثانوية ليكون قادرا على مواجهة التحديات السياسية والاجتماعية الناتجة عن العولملة.

التعريفات الاصطلاحية والإجر ائية:

تناولت الدراسة بعض التعريفات وذلك على النحو الآتي: الدور: يعرف الدور بانه مجموعة الانشطة المقصودة الهادفة المحددة في ضوء معايير عملية يمكن ملاحظتها وقياسها، وهو مجموعة من الأنشئ الأشطة

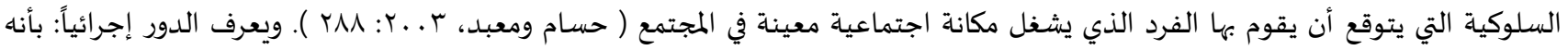

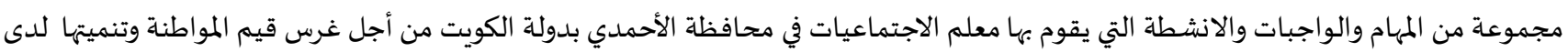

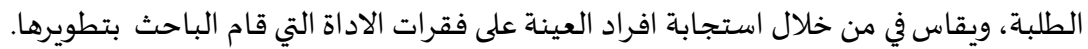

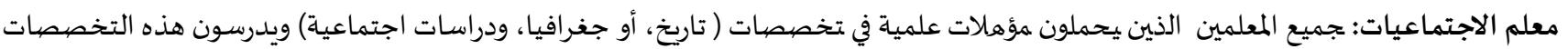
في المدارس، ويقصد بهم في هذه الدراسة المعلمون الذين يدرسون هذه المباحث في المرحلة الثانوية في محافظة الأحمدي بدولة الكويت

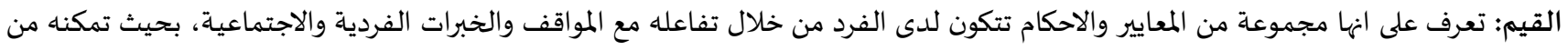
اختيار أهد اف وتوجهات لحياته يراها جيدة بتوظيف امكانياته، وتتجسد خلال الاهتمامات او الاتجاهات او السلوك العملي أو اللفظي بطريقة مباشرة

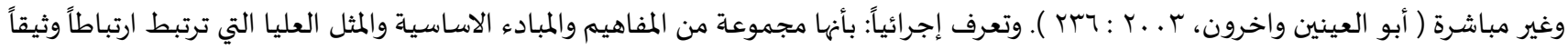

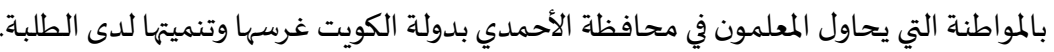
المواطنة: هي أن يعرف الفرد حقوقه ويؤدي واجباته عن طريق التربية الوطنية، وتتميز المواطنةبنوع خاص من ولاء المواطن لوطناه وخدمته في اوقات

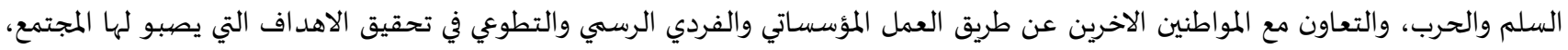

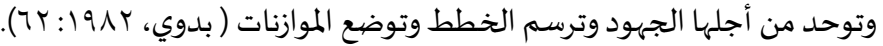

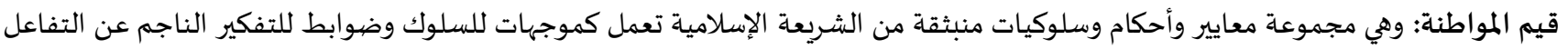

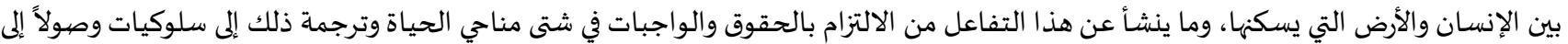

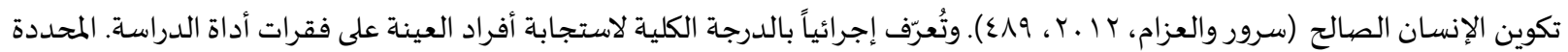

حدود ومحدددات الدراسة: اشتملت الدراسـة على الحدود والمحدددات الآتية: الحدود الموضوعية: اقتصرت الدراسة على موضوع تنمية قيم المواطنة لدى طلبة المرحلة الثانوية في الصفي الحادي عشر والثاني عشر. الحدود المكانية: طبقت هذه الدِّراسة على مدارس المرحلة الثانوية الحكومية في محافظة الأحمدي.

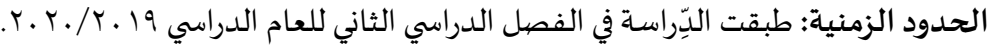

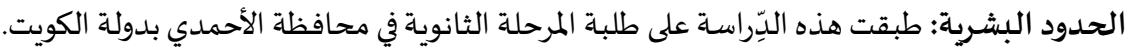

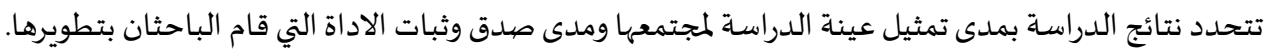

الدراسات السابقة:

يستعرض الباحثان مجموعة من الدارسات السابقة العربية والأجنبية ذات العلاقة بموضوع الدراسة الحالية، وسيتم عرضها حسب تسلسلها 
التاريخي من الأحدث إلى الأقدم على النحو التالي:

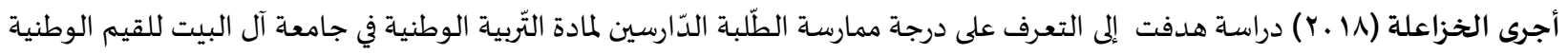

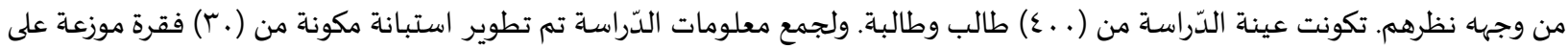

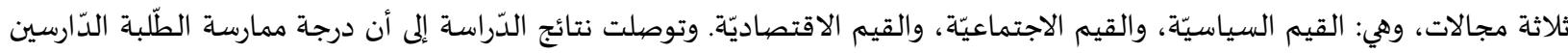

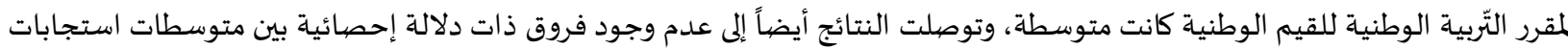

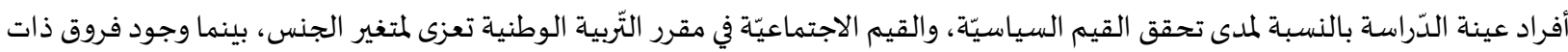

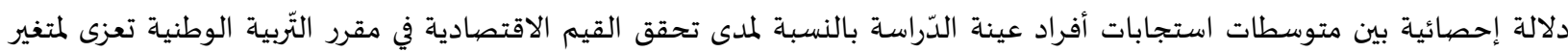

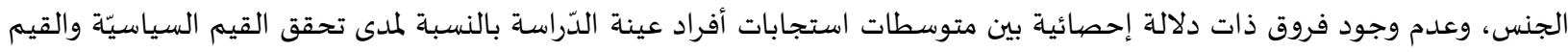

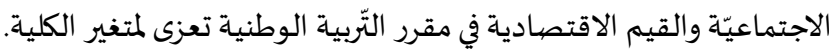

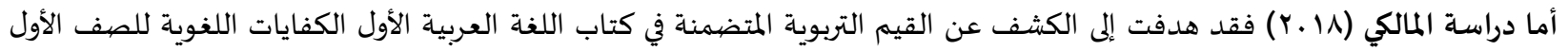

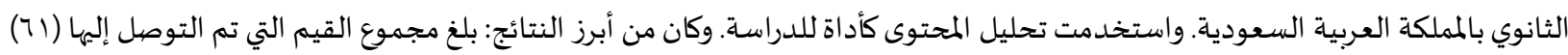

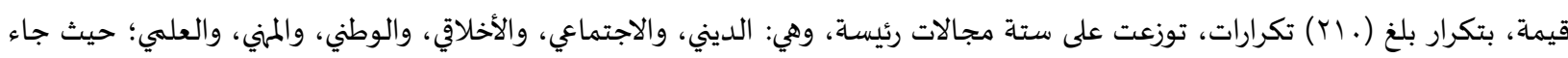

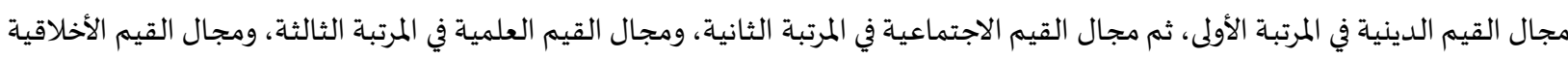

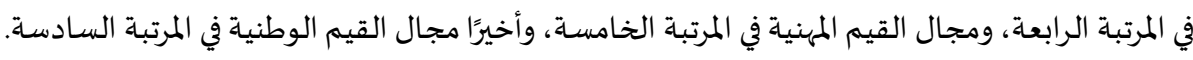

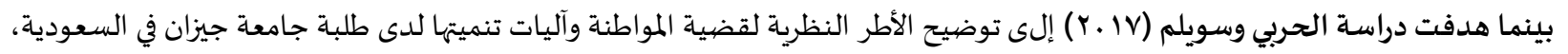

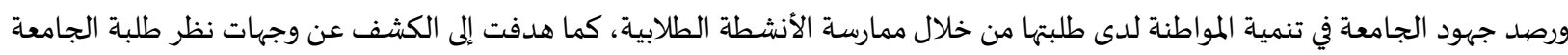

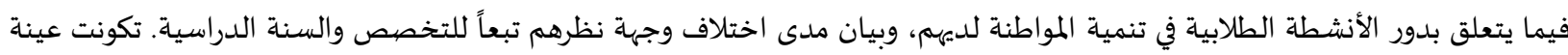

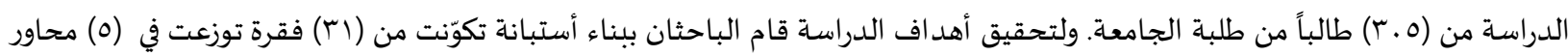

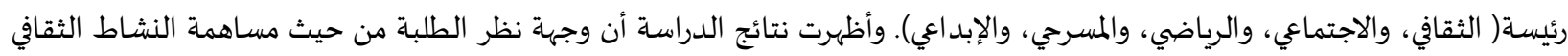

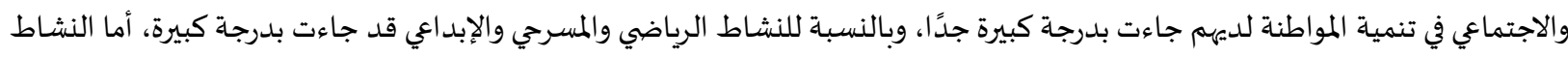

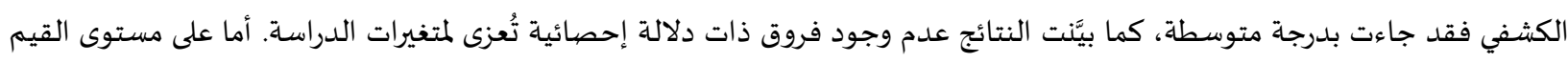
الفرعية فقد أظهرت النتائج تكرار بعض القيم على حساب البعاب البعض الآخر.

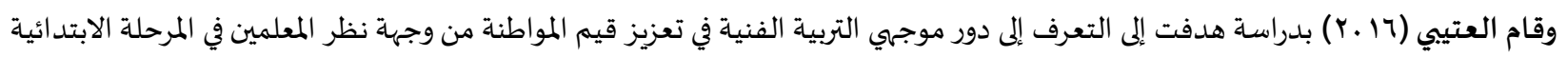

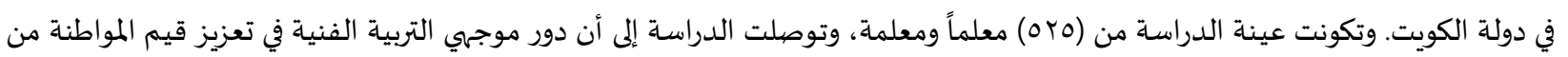

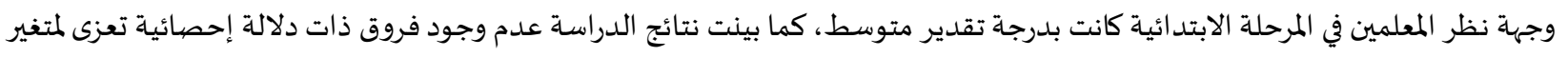
الجنس، والتخصص، والخبرة.

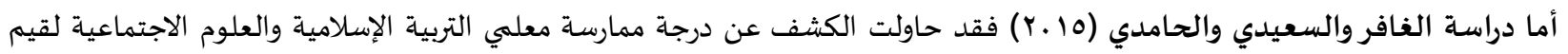

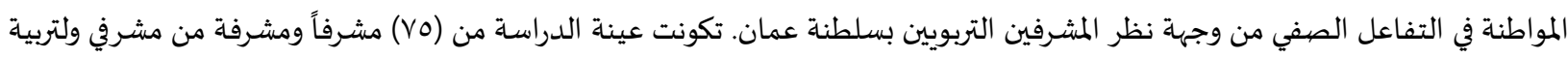

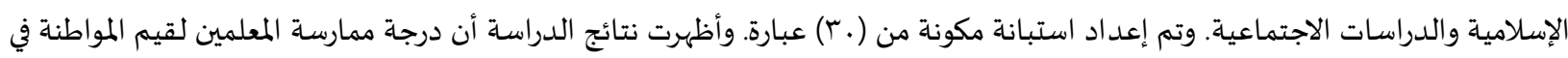

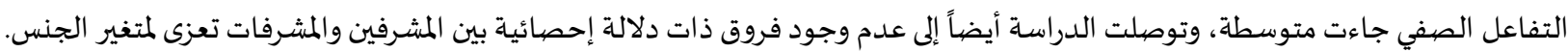

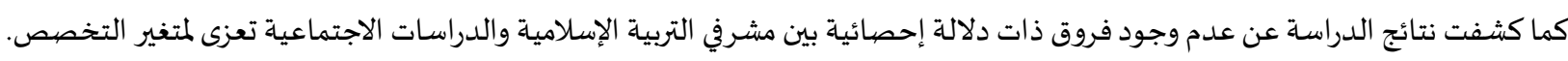

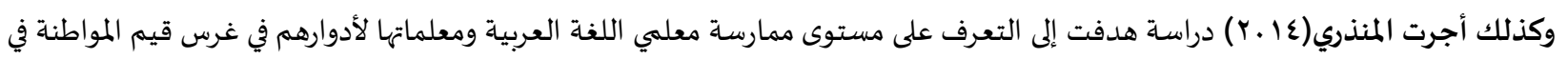

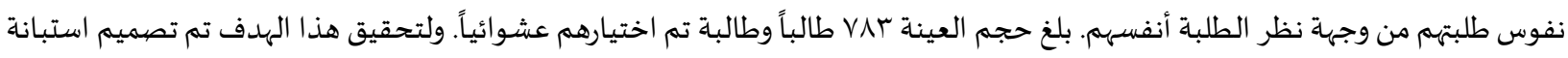

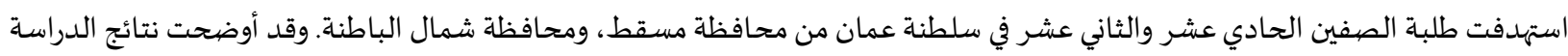

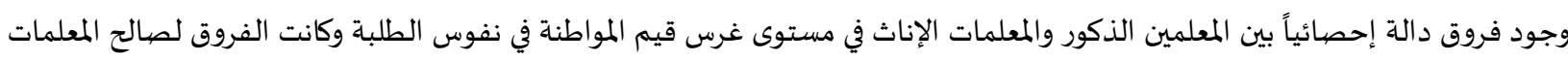

بينما قام رمضان ويوسف (ع (r) بدراسة هدفت إلى قياس مفاهيم المواطنة في كتاب الدراسات الاجتماعية للصف الخامس الأساسي ودرجة

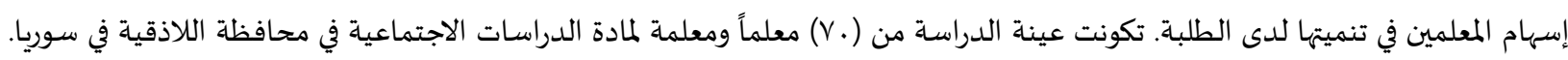

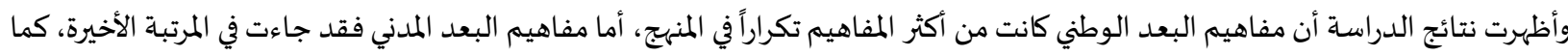

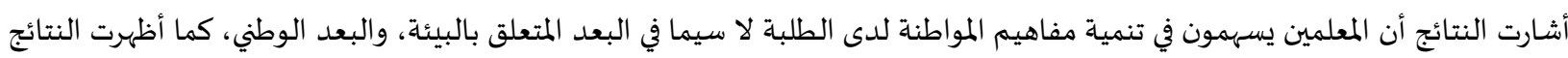


عدم وجود فروق ذات دلالة إحصائية في إسهام المعلمين حسب متغيرات الجنس والمؤهل، في حين وجدت فروق حسب متغير الخبرة لصالح

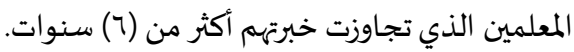

كما أجرى أودوكبونج وأوكون (Udoukpong \& Okon, 2012) دراسة هدفت إلى قياس مدى استعداد وجاهزية المعلمين لتعزيز قيم المواطنة وأهد افها في مادة الدراسات الاجتماعية، حيث تم تطبيق الدراسة على واوكون معلمي المرحلة الثانوية ومعلماتها في مدارس العاصيمة النيجيرية. وأظهرت

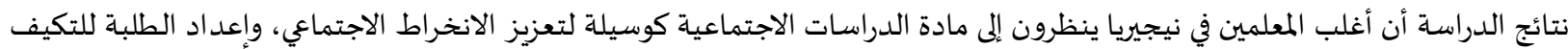

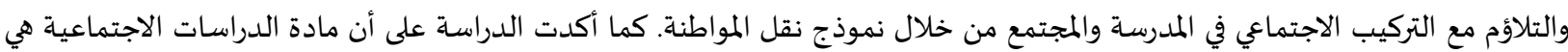

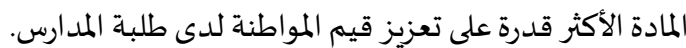

بينما هدفت دراسة مارتن وياب(Martin and Yap, 2011) إلى التعرف إلى فهم الطلبة في سنغافورة للمواطنة من خلال المسارات التعليمية.

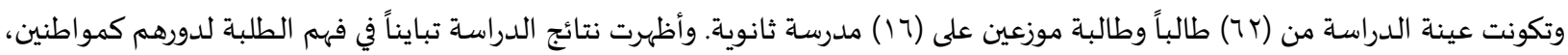

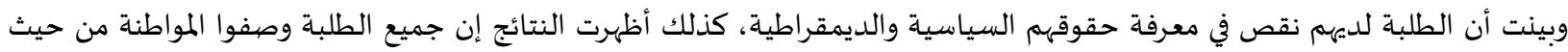
مسؤولياتهم الخاصة نحو الدولة، مثل إطاعة القوانين والمشاركة في التصويت، وبين بعضهيهم إن مفهوم المواطنة لدهيه لديه هو المحافظة على على بيئة نظيفة، أما البعض الآخر فقد بين أن المواطن الصالح هو الذي يطيع قوانين بلاده وله مستوى عالٍٍ من الثقة في الحكومة ومؤسساتها ودورها في تأمين الرفاه الاجتماعي للمواطنين.

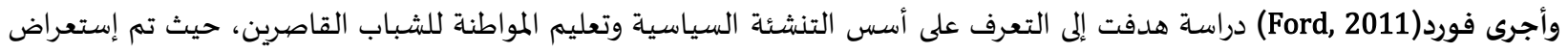

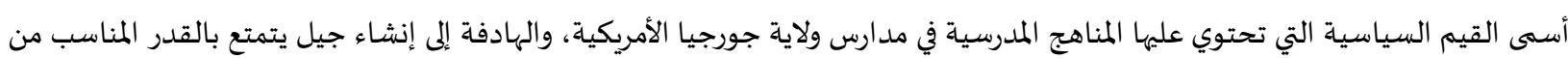

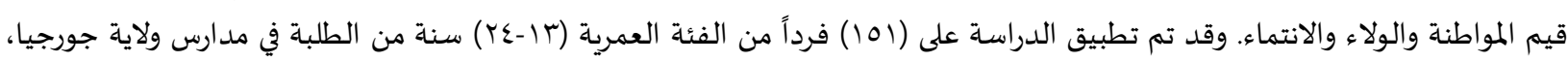

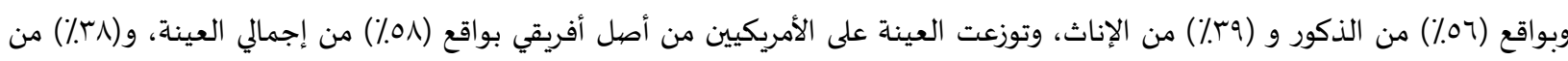

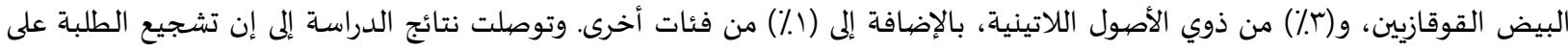

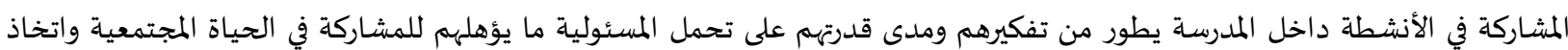

القرارات السليمة.

وأجرى يلمازوتسـدان(Yilmaz \& Tasdan,2009) دراسـة هدفت إلى استطلاع وجهات نظر معلمي المدارس الابتدائية في تركيا وتصوراتهم حول

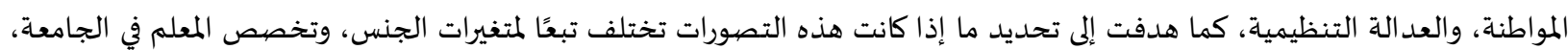

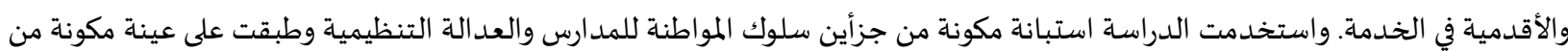

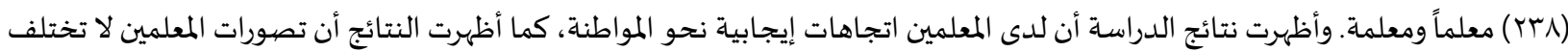
تبعًا لمتغيرات الجنس، وتخصص المعلم في الجامعةة، والأقدمية. وقام كوتسلني (Koutselini,2008) بدراسـة هدفت إلى الكشف عن تصورات الطلبة المعلمين نحو المواطنة في قبرص. وقد تكونت عينة الدراسة من (rع ا ) طالباً وطالبة من طلبة قسم التربية في جامعة قبرص. واستخدمت الباحثة استبانة لتحقيق أهداف الدراسـة، وأظهرت النتائج تقدماً في الاتجاهات نحو المواطنة بشكل إيجابي، كذلك أظهرت سلسلة متصلة من المفاهيم حول المواطنة والتي تتماشى مع الخطاب حول حقوق الإنسان.

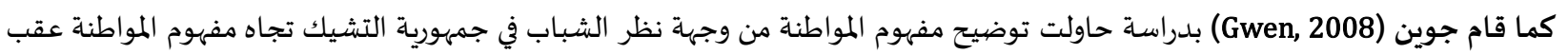

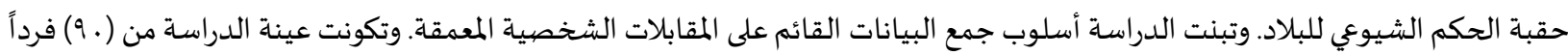
من طلبة جامعة تشارلز في العاصهمة التشيكية. وأظهرت النتائج أن تصورات الطلبة تجاه مفهوم المواطنة تمثلت في التحلي بالنزعة الوطئة الوطنية والانتماء للوطن، والتمتع بالحريات والحقوق والمساواة. يتضح من استعراض الدراسات السـابقة ما يلي:

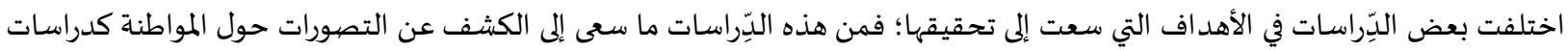

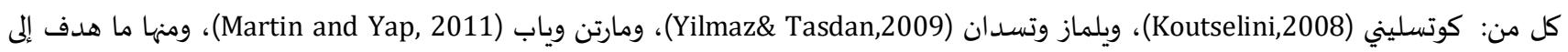

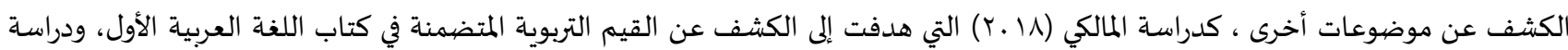

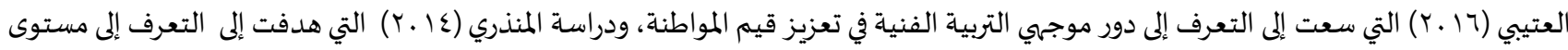

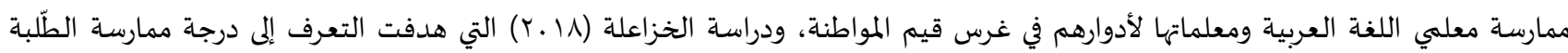

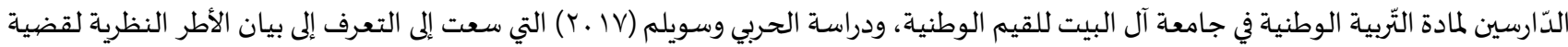

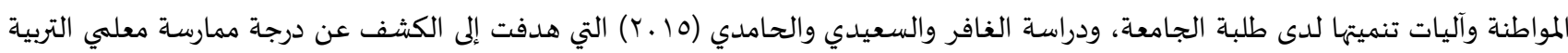

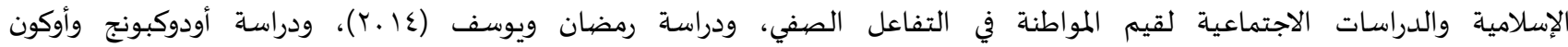


(Udoukpong\&Okon, 2012)

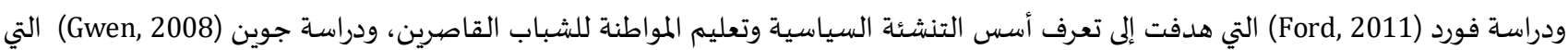
هدفت إلى توضيح مفهوم المواطنة من وجهة نظر الشباب.

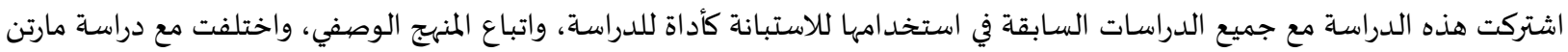

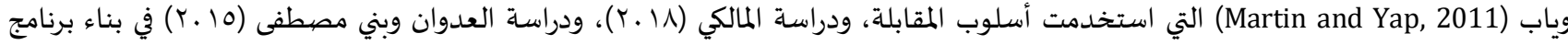
تدريبيّ.

كذلك تباينت المجتمعات التي تم اختيارها في الدراسات السابقة حيث تختلف هذه الدراسة عن الدراسات السابقة من حيث الفئة المستجيبة اذ

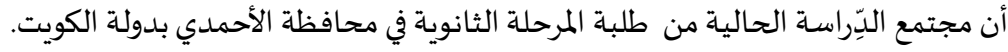

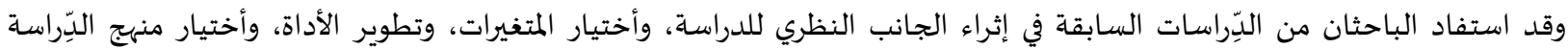

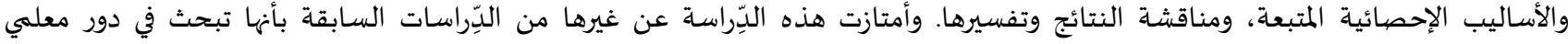

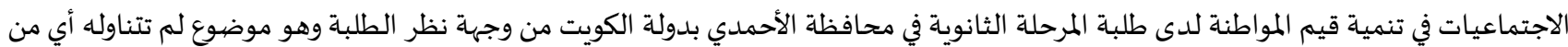
الدراسات السابقة

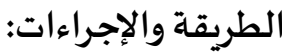

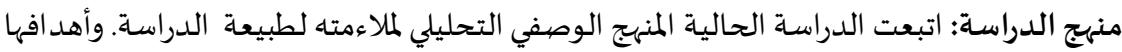

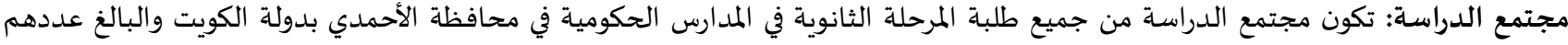

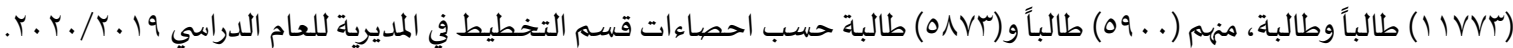

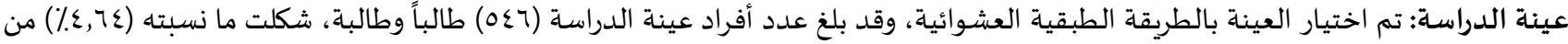
مجتمع الدراسة والجدول( (1) يبين توزيع أفراد عينة الدراسة حسب متغيرات الدراسة: جدول( (1): توزيع أفراد عينة الدراسة حسب الجنس والصف والجنسية والتخصص

\begin{tabular}{|c|c|c|c|}
\hline العدد & فئة المتغير & المتغير & \\
\hline rrI & ذكر & \multirow[t]{2}{*}{ الجنس } & \\
\hline rvo & أنثى & & \\
\hline $0 \leqslant 7$ & & & المجموع \\
\hline$r 71$ & 4.1 & \multirow[t]{2}{*}{ الصف } & \\
\hline rVA & ث.r & & \\
\hline $0 \leqslant 7$ & & & المجموع \\
\hline $0 . r$ & كويتي & \multirow[t]{2}{*}{ الجنسية } & \\
\hline$\varepsilon \varepsilon$ & غير كويتي & & \\
\hline $0 \leqslant 7$ & & & المجموع \\
\hline TV. & علمي & \multirow[t]{2}{*}{ الفرع } & \\
\hline rVר & أدبي & & \\
\hline $0 \leqslant 7$ & & & المجموع \\
\hline
\end{tabular}

أداة الدراسة:

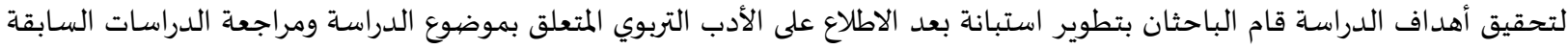

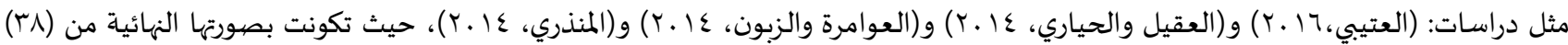
فقرة توزعت في أربعة مجالات هي: الانتماء والولاء, والوعي السياسي ,والعمل الجماعي , والتسامح واحترام الترام الغير. صبدق المحتوى: تم التحقق من دلالات الصيدق باستخدام صدق المحكمين من خلال توزيع الاستبانة بصورتها الأولية على (ملا) محكماً من أساتذة الجامعات

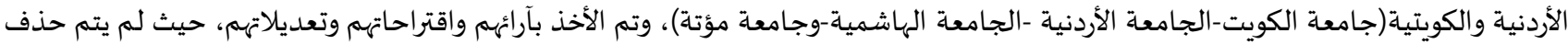
أي من فقرات الاستبانة، في ضوء تعديلاتهم، وذلك بنسبة اتفاق (.A.^).

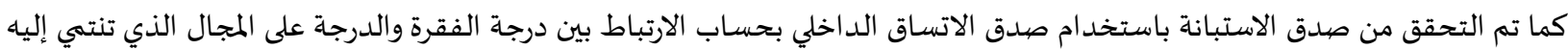

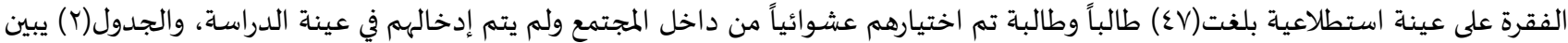
معاملات الارتباط: 
جدول(Y): صدل البناء الداخلي للأداة بحساب معامل ارتباط بيرسون بين الدرجة على الفقرة والدرجة الفرعية على المجال الذي تنتهي لله الفقرة.

\begin{tabular}{|c|c|c|c|c|c|c|c|}
\hline معامل الارتباط & الفقرة & معامل الارتباط & الفقرة & معامل الارتباط & الفقرة & معامل الارتباط & الفقرة \\
\hline \multicolumn{2}{|c|}{ التسامح واحترام الآخر } & \multicolumn{2}{|c|}{ العمل الاجتماعي } & \multicolumn{2}{|c|}{ الوعي السياسي } & \multicolumn{2}{|c|}{ الانتماء والولاء } \\
\hline${ }^{*} ., \Gamma \varepsilon \wedge$ & rq & ${ }^{*}$, , rvq & $r$ & $*, r \leqslant \varphi$ & ir & ${ }^{* *} ., \pi T r$ & 1 \\
\hline${ }^{* *} ., 01 \varepsilon$ & $r$. & ${ }^{* *} ., 0 . \mathrm{r}$ & KY & **., \&YT & ir & $*_{., 217}$ & $r$ \\
\hline 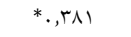 & $r$ & ${ }^{* *} ., 07 \mathrm{~V}$ & $r$ & ${ }^{* *}$, , V17 & $1 \varepsilon$ & ${ }^{* *}$, or & $r$ \\
\hline *.,711 & Tr & **.,Tr. & $r \varepsilon$ & **.,orq & 10 & ${ }^{* *} ., 01 \mathrm{~V}$ & $\varepsilon$ \\
\hline 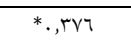 & $r r$ & **., oor & ro & **., เ9. & 17 & **., orV & o \\
\hline${ }^{* *} .$, \&oV & $r \varepsilon$ & ${ }^{* *} ., \varepsilon 77$ & r & ${ }^{* *} .,\{07$ & iv & $*^{* *}$, , \{八। & 7 \\
\hline${ }^{* *} ., \varepsilon \vee \wedge$ & ro & **., $\{1 \varepsilon$ & rv & *., rAT & 11 & $* * ., 071$ & v \\
\hline${ }^{* *} .$, OVT & ry & **.,010 & ru & $*$, * r & 19 & **, & $\Lambda$ \\
\hline${ }^{* *} ., \leq \varepsilon \varepsilon$ & $r v$ & & & $*, 719$ & $r$. & **., \&.q & 9 \\
\hline *.,raY & $\mu_{\Lambda}$ & & & & & ${ }^{* *} ., 09 Y$ & 1. \\
\hline & & & & & & ${ }^{* *}$., Vor & 11 \\
\hline
\end{tabular}

(*) دالة عند مستوى الدلالة (0.05) , (*) دالة عند مستوى الدلالة (0.01)

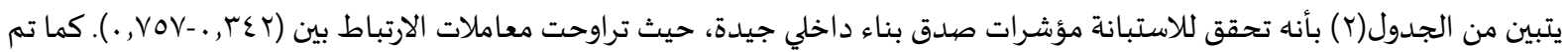

حساب معامل الارتباط بين الدرجة على المجال والدرجة الكلية على الاستبانة كما في الجدول(ب):

جدول(ץ): معامل الارتباط بين الدرجة على المجال والدرجة الكلية على الاستبانة

\begin{tabular}{|c|c|}
\hline معامل الثبات & المجال \\
\hline **, VIY & الانتماء والولاء \\
\hline **, V170 & الوعي السياسي \\
\hline **.,7rV & العمل الاجتماعي \\
\hline${ }^{* *} ., \mathrm{V} 乏 \wedge$ & التسامح واحترام الآخر \\
\hline
\end{tabular}

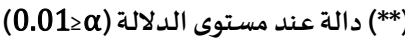

ثبات الاستبانة:

تم التحقق من دلالات ثبات الاستبانة باستخدام معادلة كرونباخ ألفا للاتساق الد اخلي على ذات العينة الاستطلاعية (ن=Vع)، والجدول(ع) يبين

معاملات ثبات الاستبانة:

جدول(ع): معاملات ثبات الاستبانة

\begin{tabular}{|c|c|}
\hline كرونباخ ألفا & المجال \\
\hline$\cdot, \Lambda$ & الانتماء والولاء \\
\hline.,$\wedge 7$ & الوعي السياسي \\
\hline.,$\lambda r$ & العمل الاجتماعي \\
\hline$\cdot, \wedge \mathrm{V}$ & التسامح واحترام الآخر \\
\hline., 9 . & الكلي \\
\hline
\end{tabular}

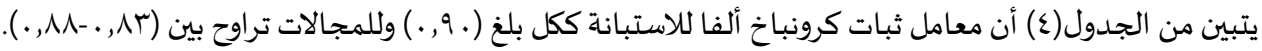

تصحيح الاستبانة:

تتم الاستجابة على الاستبانة بحسب تدريج Likert الخماسي بدرجات موافقة : كبيرة جداً، وكبيرة، ومتوسطة، ودرجة غير موافق كبيرة، وغير موافق بدرجة كبيرة جداً)، وتعطى الدرجات (0، ع، ب، ؟ ، ، () على الترتيب، ويتم الحكم على درجة الموافقة بالاعتماد على المعيار التالي:

\begin{tabular}{|c|c|}
\hline المستوى بالنسبة للمتوسط الحسابي & لمتوسط الحسابي \\
\hline منخفض & $r, r T-1$ \\
\hline متوسط & $r, 77-r, r \varepsilon$ \\
\hline مرتفع & $0-r, T V$ \\
\hline
\end{tabular}

نتائج الدراسـة ومناقشتها:

النتائج المتعلقة بالسؤال الأول ومناقشتـه ونصها: ما دورمعلمي الاجتماعيات في تنمية قيم المواطنة لدى طلبة المرحلة الثانوية؟ للإجابة عن السؤال تم حساب المتوسطات الحسابية والانحرافات المعيارية، والجدول (0) يبين ذلك: دونئ: 
جدول(0): المتوسطات الحسابية والانحر افات المعيارية لمجالات دور معلمي الاجتماعيات في تنمية قيم المواطنة لدى طلبة المرحلة الثانوية مرتبة تنازليا حسب المتوسط

\begin{tabular}{|c|c|c|c|c|}
\hline المستوى & الرتبة & المعياري & المستوسط & المجال \\
\hline مرتفع & 1 & $\cdot, \mathrm{Vq}$ & $\varepsilon, . V$ & الانتماء والولاء \\
\hline مرتفع & r & $\cdot, \lambda 1$ & $\varepsilon, . r$ & الوعي السياسي \\
\hline مرتفع & r &., 10 & $r, \wedge 9$ & العمل الاجتماعي \\
\hline مرتفع & $\varepsilon$ &., 91 & $r, v \varepsilon$ & التسامح واحترام الآخر \\
\hline مرتفع & - &., $\mathrm{VT}$ & $r, 9 \leq$ & الكلي \\
\hline
\end{tabular}

يلاحظ من خلال الجدول (0) أن دور معلمي الاجتماعيات في تنمية قيم المواطنة لدى طلبة المرحلة الثانوية جاء بمستوى مرتفع وبمتوسط حسابي

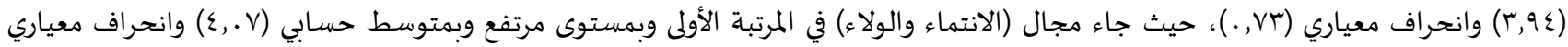

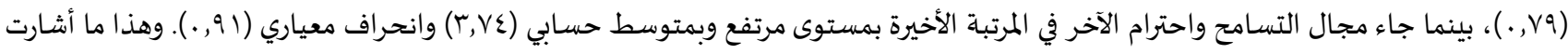

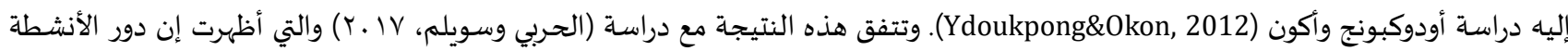

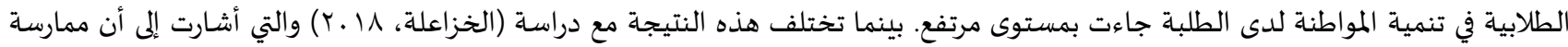

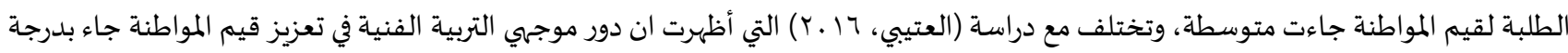

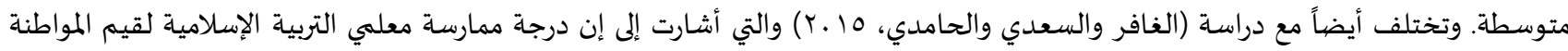

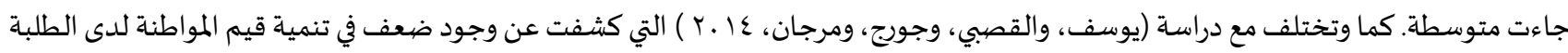

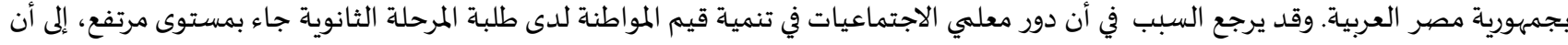

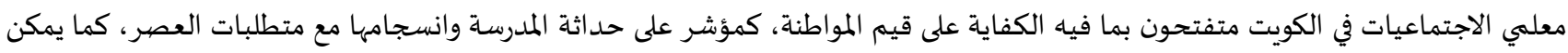

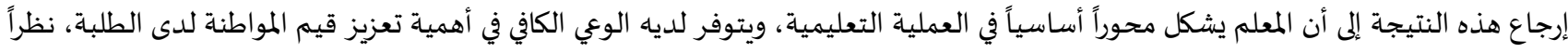

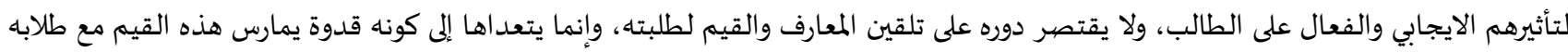

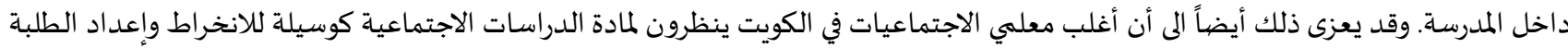

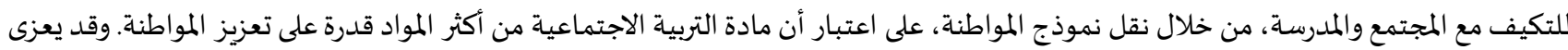

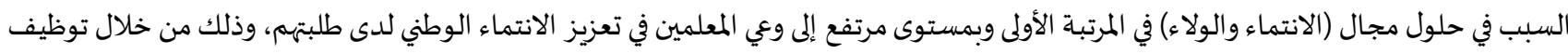

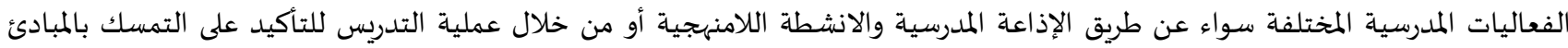

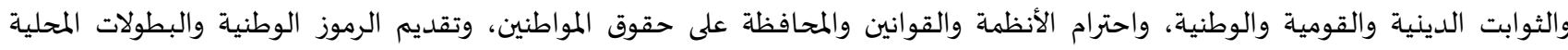

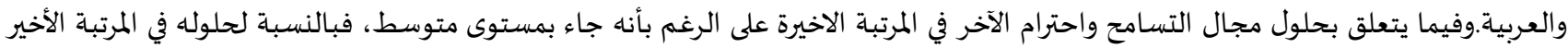

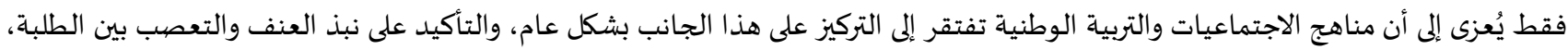

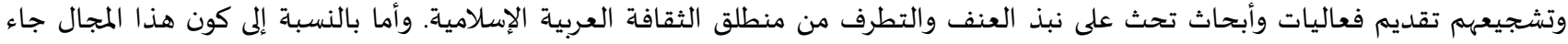

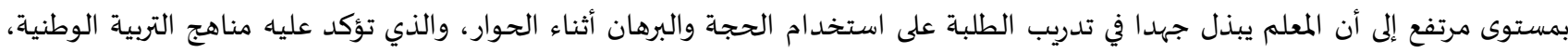

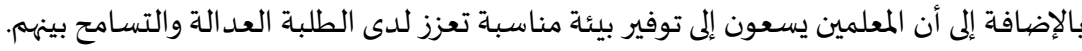

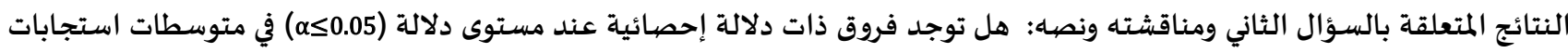

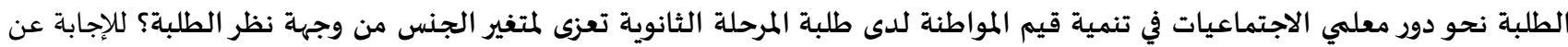

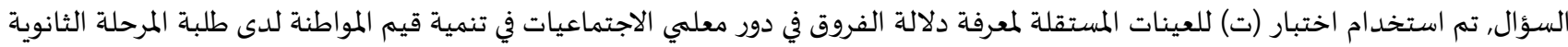
تعزى لمتغير الجنس, والجدول (7) يوضح ذلك:

\begin{tabular}{|c|c|c|c|c|c|c|c|}
\hline مستوى الدلالة & قيمة(ت) & درجة الحرية & الانحرافات المعيارية & المتوسطات الحسابية & 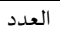 & الجنس & المجال \\
\hline \multirow[t]{2}{*}{., } & \multirow[t]{2}{*}{$\varepsilon, \backslash \wedge \varepsilon-$} & \multirow[t]{10}{*}{$0 \leqslant \varepsilon$} &.,$\Lambda 7$ & $r, q r$ & 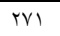 & ذكر & \multirow[t]{2}{*}{ الولاءوالانتماء } \\
\hline & & &., $7 \uparrow$ & $\varepsilon, r)$ & rVo & أنثى & \\
\hline \multirow[t]{2}{*}{$+\ldots$} & \multirow[t]{2}{*}{$r, 01 \Lambda_{-}$} & &.,$\Lambda 7$ & $r, q$. & $T M I$ & ذكر & \multirow[t]{2}{*}{ الوعي السياسي } \\
\hline & & &.,$V Y$ & $\varepsilon, 1 \varepsilon$ & rVo & أنثى & \\
\hline \multirow[t]{2}{*}{ 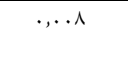 } & \multirow[t]{2}{*}{$r, T \xi r-$} & &., 91 & $r, v q$ & $T M I$ & ذكر & \multirow[t]{2}{*}{ العمل الاجتماعي } \\
\hline & & &., $\mathrm{Vr}$ & $r, 91$ & Tro & أنثى & \\
\hline \multirow[t]{2}{*}{., .14} & \multirow[t]{2}{*}{ r,or)- } & &., $9 \varepsilon$ & $r, \mathrm{r} \wedge$ & TWI & ذكر & \multirow[t]{2}{*}{ التسامح واحترام الآخر } \\
\hline & & &.,$\wedge$ & $r, \Lambda \Lambda$ & rVo & أنثى & \\
\hline \multirow[t]{2}{*}{$\therefore, \ldots$} & \multirow[t]{2}{*}{$r, v \cdot 1-$} & &., $\mathrm{Vq}$ & $r, \lambda r$ & $T M I$ & ذكر & \multirow[t]{2}{*}{ الكلي } \\
\hline & & &., 70 & $\varepsilon, .7$ & rVo & أنثى & \\
\hline
\end{tabular}


يتبين من النتائج الواردة في الجدول(7) وجود فروق ذات دلالة إحصائيةً عند مستوى دلالة (م) ه . ,.) في دور معلمي الاجتماعيات في تنمية قيم

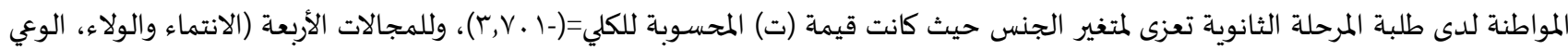

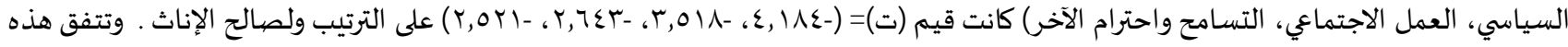

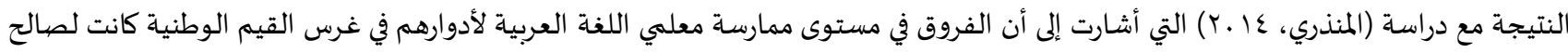

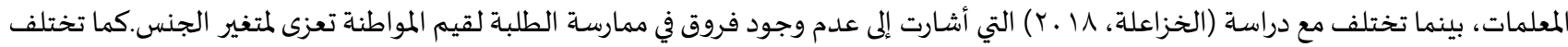

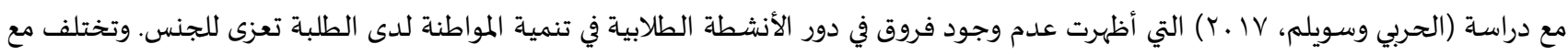

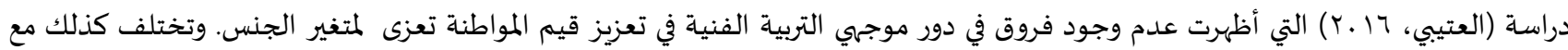

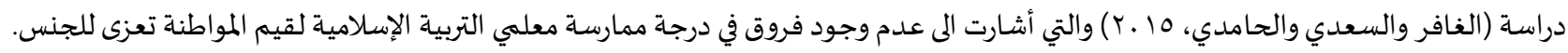

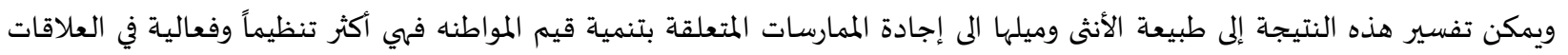

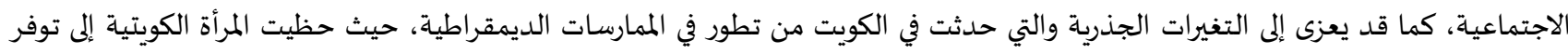

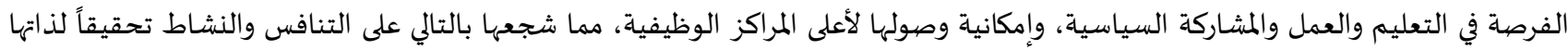

$$
\text { وخدمة لوطنها. }
$$

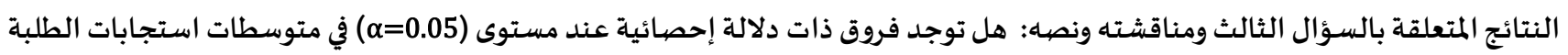
نحو دور معلهي الاجتماعيات في تنمية قيم المواطنة لدى طلبة المرحلة الثانوية تعزى لمتغير الصفف من وجهة نظر الطلبة؟ للإجابة عن السؤال, تم

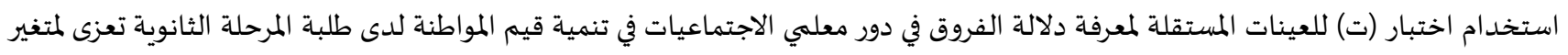
الصف والجدول(V) يبين ذلك:

جدول(V): نتائج اختبار(ت) للعينات المستقلة لمعرفة دلالة الفروق في دور معلمي الاجتماعيات في تنمية قيم المواطنة لدى طلبة المرحلة الثانوية تبعاً لمتغير الصفف

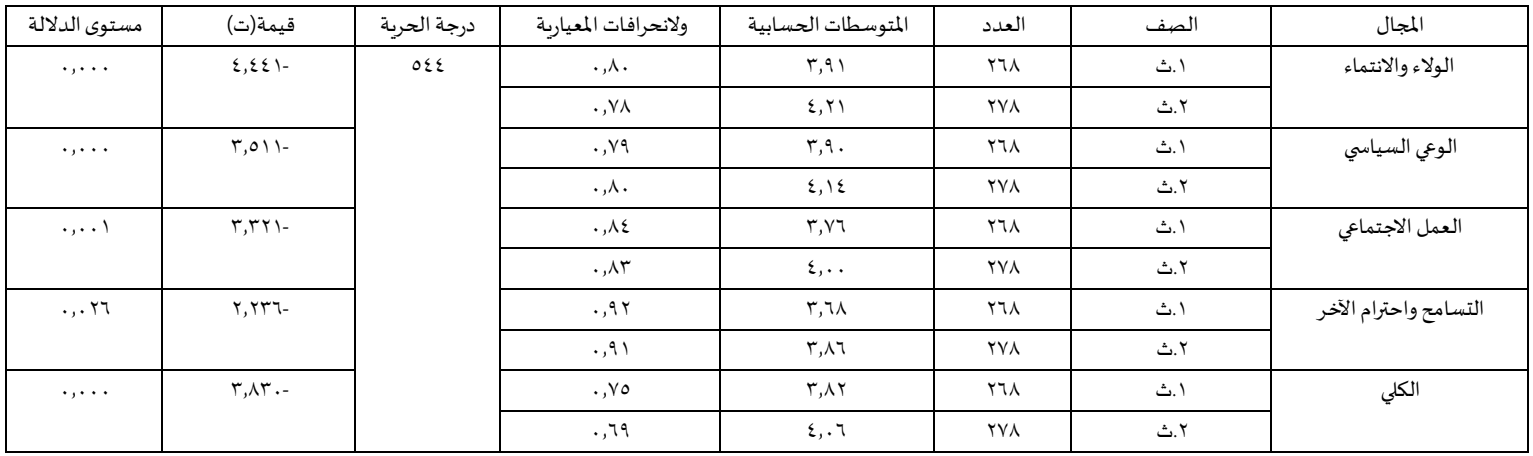

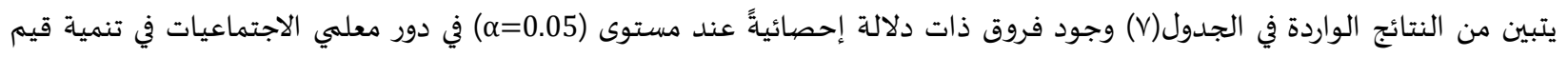

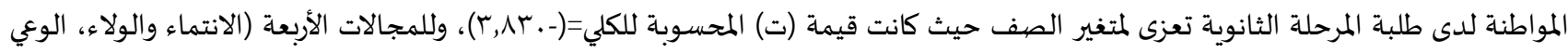

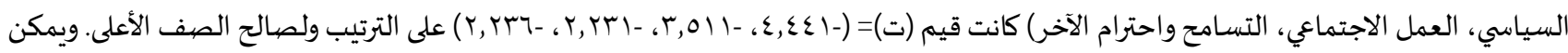

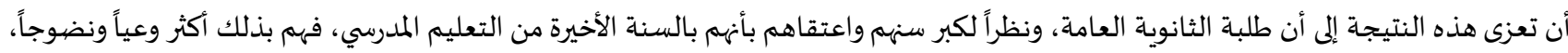

كما قد يعزى ذلك إلى أن المعلمين يركزون على هؤلاء الطلبة كونهم سيكونون صورتهم في الحياة الجامعية والعملية بعد الثانوية العامة.

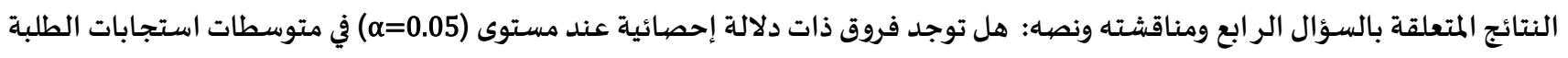

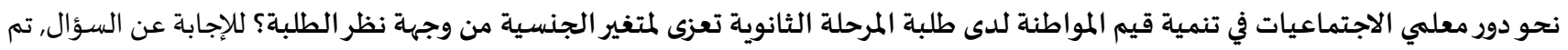

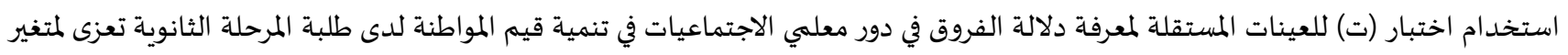
الجنسية, والجدول (ᄉ) يوضح ذلك: 
جدول(^): نتائج اختبار (ت) للعينات المستقلة لمعرفة دلالة الفروق في دور معلمي الاجتماعيات في تنمية قيم المواطنة لدى طلبة المرحلة الثانوية تبعاً لمتغير الجنسية

\begin{tabular}{|c|c|c|c|c|c|c|c|}
\hline مستوى الدلالة & قيمة(ت) & درجة الحرية & ولانحرافات المعيارية & المتوسطات الحسابية & العدد & الجنسية & المجال \\
\hline \multirow[t]{2}{*}{,$\ldots 1$} & \multirow[t]{2}{*}{$r, \sum q r$} & \multirow[t]{7}{*}{$0 \leqslant \varepsilon$} &., $\mathrm{V} 7$ & $\varepsilon, 1$. & $0 . r$ & كويتي & \multirow[t]{2}{*}{ الولاءوالانتماء } \\
\hline & & & $1, . r$ & $r, 71$ & $\varepsilon \varepsilon$ & غير كويتي & \\
\hline,$\ldots 1$ & $r, r \leq V$ & &., 9 & $r, 0 \Lambda$ & $\varepsilon \varepsilon$ & غير كويتي & الوعي السياسي \\
\hline,$\ldots$ & $r, 79 V$ & & 佂 & $r, q r$ & $0 . r$ & كويتي & العمل الاجتماعي \\
\hline., .19 & r,rur & & $1, . \varepsilon$ & $r, \varepsilon 1$ & $\varepsilon \varepsilon$ & غير كويتي & التسامح واحترام الآخر \\
\hline \multirow[t]{2}{*}{$\ldots$} & \multirow[t]{2}{*}{$r, 7 r)$} & & $\cdot,(1)$ & $r, q \vee$ & $0 . r$ & كويتي & \multirow[t]{2}{*}{ 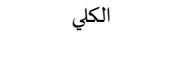 } \\
\hline & & & .,95 & $r, 0$. & $\varepsilon \varepsilon$ & غير كويتي & \\
\hline
\end{tabular}

يتبين من النتائج الواردة في الجدول(^) وجود فروق ذات دلالة إحصائيةً عند مستوى (م=0.05) في دور معلمي الاجتماعيات في تنمية قيم

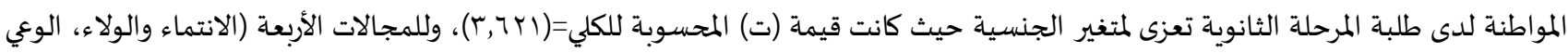

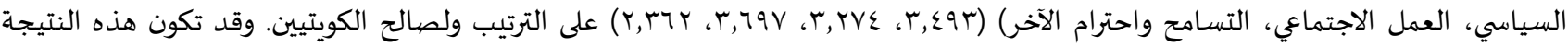

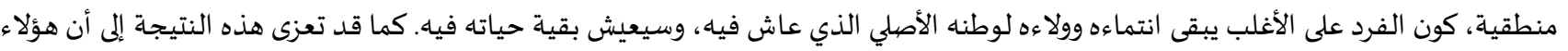

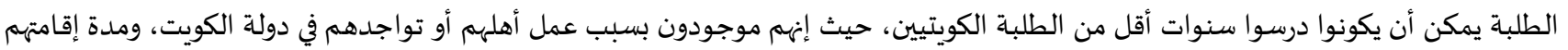

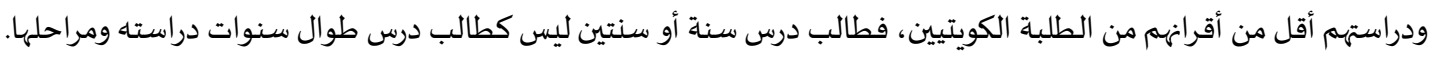

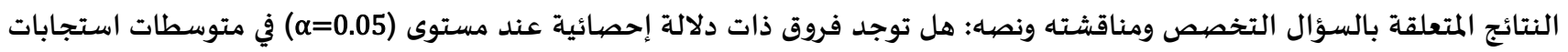
الطلبة نحو دور معلمي الاجتماعيات في تنمية قيم المواطنة لدى طلبة المرحلة الثانوية تعزى لمتغير التخصص من وجهة نظر الطلبة؟ للإجابة عن

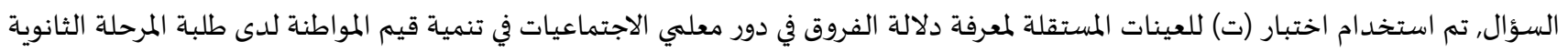
تعزى لمتغير التخصص, والجدول (9) يوضح ذلك:

جدول(9): نتائج اختبار (ت) للعينات المستقلة لمعرفة دلالة الفروق في دورمعلمي الاجتماعيات في تنمية قيم المواطنة لدى طلبة المرحلة الثانوية تبعاً لمتغير التخصص

\begin{tabular}{|c|c|c|c|c|c|c|c|}
\hline مستوى الدلالة & قيمة(ت) & درجة الحرية & ولانحرافات المعيارية & المتوسطات الحسابية & العدد & التخصص & \\
\hline \multirow[t]{2}{*}{., .99} & \multirow[t]{2}{*}{ 1,70r } & \multirow[t]{7}{*}{$0 \leqslant \varepsilon$} &., $\mathrm{V} \varepsilon$ & $\varepsilon, I r$ & TV. & علمي & \multirow[t]{2}{*}{ الولاءوالانتماء } \\
\hline & & & . Ar & $\varepsilon, .1$ & TVT & أدبي & \\
\hline., $0 \leqslant$. & . & &., 17 & $\varepsilon, \ldots$ & YVI & أدبي & الوعي السياسي \\
\hline.,$r \varepsilon \wedge$ & ., १ะ. & & $\cdot, \lambda$ & $r, q r$ & rV. & علمي & العمل الاجتماعي \\
\hline .,TYA & $1, r \cdot 7$ & &., 90 & $r, v r$ & TVT & أدبي & التسامح واحترام الآخر \\
\hline \multirow[t]{2}{*}{., $19 \varepsilon$} & \multirow[t]{2}{*}{$1, r \ldots$} & &., TV & $r, 91$ & TV. & علمي & \multirow[t]{2}{*}{ الكلي } \\
\hline & & &., $\mathrm{Vq}$ & $r, q$. & rVT & أدبي & \\
\hline
\end{tabular}

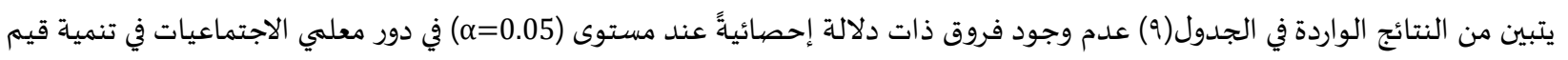

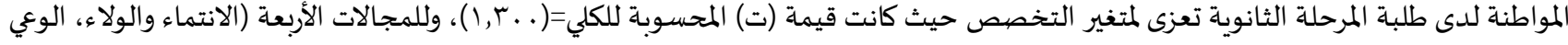

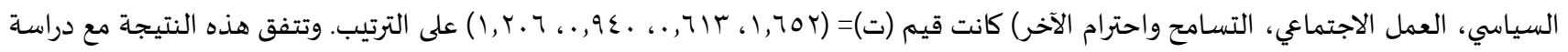

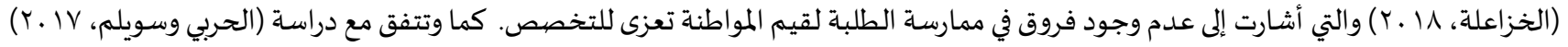

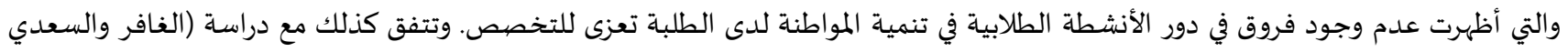

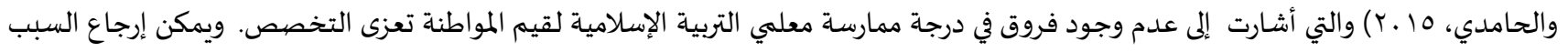
في عدم وجود فروق ذات دلالة إحصائيةً عند مستوى دلالة (م)0. . .) في دور معلمي الاجتماعيات في تنمية قيم المواطنة لدى طلبة المرحلة الثانوية

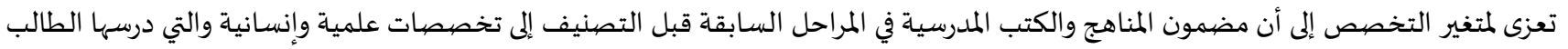
وعلى مدار ( ـ ا سنوات هي ذاتها، وهي المرحلة التي يكتسب بها الطالب المواطنة وقيمها، كما أههم يدرسون مادة التربية الوطنية ذاتها في المرحلة الثانوية، 
علاوة على إنهم يعيشون في بيئة واحدة من حيث إنهم في نفس المدرسة، ولذا فهم يمارسون نفس الفعاليات والأنشطة الوطنية والاحتفالات الوطنية والإذاعة المدرسية.

التوصيات:

بناءً على نتائج الدراسة يمكن التوصياة بما يلي: ضرورة أن يقوم المعلمين بتدريب الطلبة على تحمل المسؤولية من خلال تكليفهم بالواجبات. أن تقوم وزارة التربية والتعليم بتطوير مناهج التربية الاجتماعية وبشكل مستمر وفي ضوء التطورات والمستجدات. ضرورة تضمين مناهج التربية الاجتماعية بيان أخطار التقليد الأعمى للثقافات الأخرى، ونبذ العنف والتعصب بين الطلبة. ضرورة أن يتم تعزيز قيم المواطنة في نفوس الطلبة وبشكل خاص لدى الطلبة الذكور، وذلك من خلال تفعيل مدارس الذكور للأنشطة والفعاليات التي تعزز قيم المواطنة لديهم.

ضرورة أن تقوم وزارة التربية بإثراء المواد الدراسية للصف الأول الثانوي بقيم المواطنة. التركيز على إشراك جميع الطلبة وخاصة الطلبة من الجنسيات غير الكويتية في جميع الأنشطة والفعاليات التي تعزز قيم المواطنة. إجراء دراسـة مماثلة على عينات وفئات أخرى مثل طلبة الجامعات وطلبة المرحلة الأساسية.

المراجع:

أولاً: المراجع العربية:

ا. إبراهيم، ش، وإبراهيم، ن. (1 . .ب). "تطوير مناهج التعليم لتنمية المواطنة في الألفية الثالثة لدى التلاميذ بالمرحلة الثانوية: دراسة تجريبية". المركز القومي للبحوث التربوية والتنمية. القاهرة.

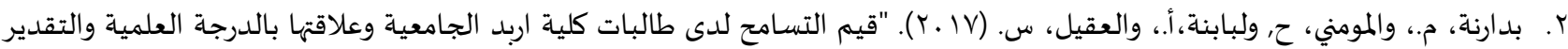

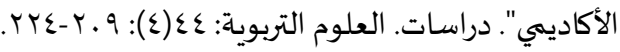

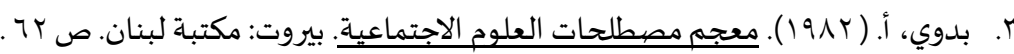
ع. براهمة، ن. (^. . r). "تطوير منهاج التربية الوطنية والمدنية في ضوء خصيائص المواطنة الصالحة وقياس أثره في اكتساب مفاهيم المواطنة

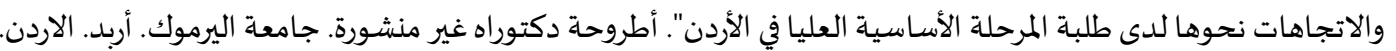

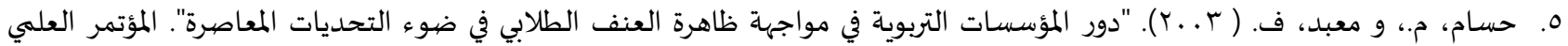

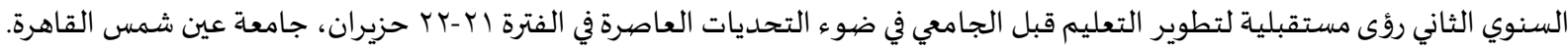

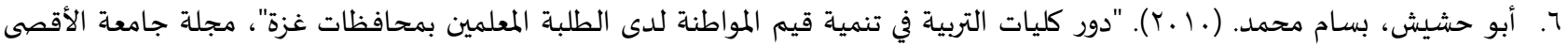

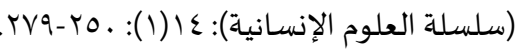
V. الحفظي، ع. ( . . . ا). "دور التربية الوطنية في تنمية المواطنة في المجتمع السعودي, رسالة ماجستير غير منشورة". التربية الإسلامية والمقارنة. جامعة أم القرى. مكة المكرمة. المملكة العربية السعودية.

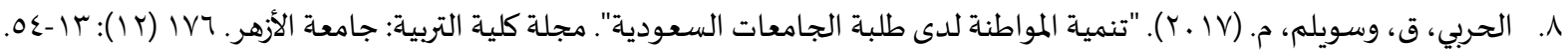

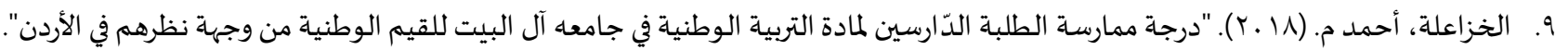

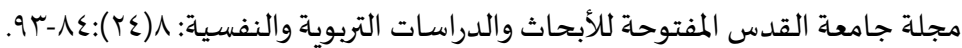
• ا. خضر، فخري رشيد. (1) . ب). "اثر استخدام القضايا الجدلية في التدريس على تحصيل طلبة الصف السابع الأساسي في مادة التربية الوطنية

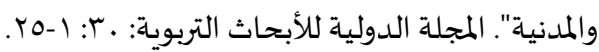
ا ا. رمضيان، ع، ويوسف، آ. (ع ا ـ r). "مفاهيم المواطنة في كتاب الدراسات الاجتماعية للصف الخامس الأساسي ودرجة إسهام المعلمين في تنميتها".

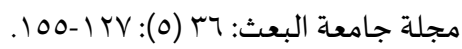
Y I زهاج، ح. (V ا • Y). "دور الأستاذ في تنمية قيم المواطنة لدى تلاميذ التعليم المتوسط". رسالة ماجستير غير منشورة. جامعة زيان عاشور الجلفة. الجزائر. rا.ـسرور، ف، العزام، م. (r ا.ب). "دور مناهج التربية الإسلامية المطورة في تنمية قيم المواطنة الصالحة لدى طلاب المرحلة الأساسية العليا من

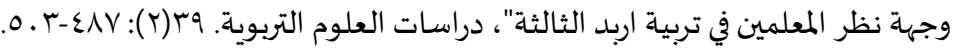


ع ا. السليم، ب. (10 ـ ب). "القيم التربوية المتضمنة بالأناشيد الواردة في كتب لغتنا العربية لصفوف المرحلة الأساسية الأولى في الأردن". مجلة دراسات

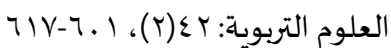

ا ـ أبو سنينة، ع.، وغانم، ب. (1 ا ـ †). "حقوق المواطنة وواجباتها كما يراها معلمو الدراسات الاجتماعية في مدارس وكالة الغوث الدولية في الأردن".

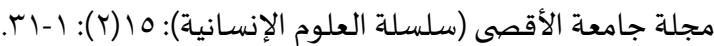

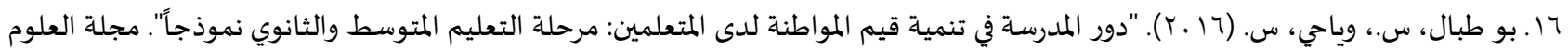

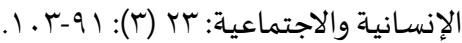

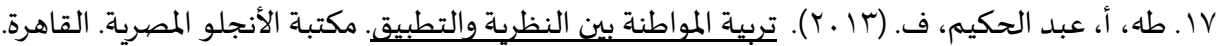
11. العتيبي، ح. (7 ا ـ †). "دور موجهي التربية الفنية في تعزيز قيم المواطنة من وجهة نظر المعلمين في المرحلة الابتدائية في دولة الكويت". رسالة ماجستير غير منشورة. جامعة آل البيت. المفرق. الأردن. 9 ا. العدوان، ز، بني مصطفى، ف. (0 ـr). "أثر برنامج تدريبيّ في تنمية مبادئ المواطنة العالميّة لدى معلمي التاريخ في الأردن". مجلة دراسات العلوم

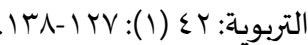

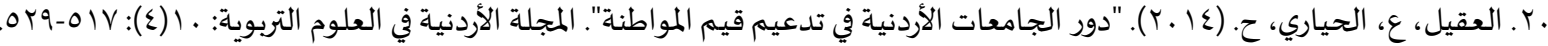

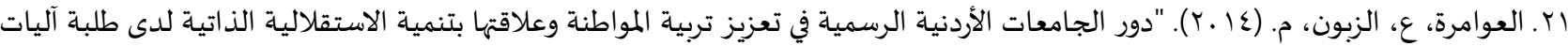

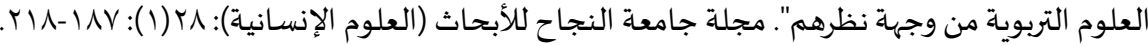

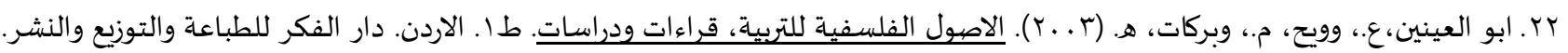

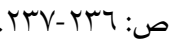

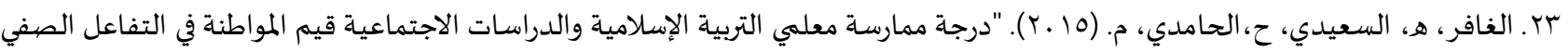

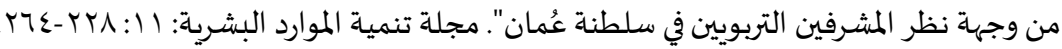

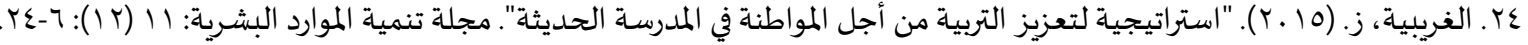

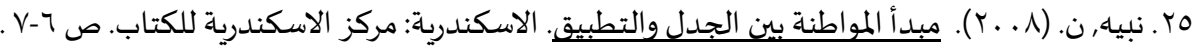
جا. فرج, ا. ( ا . . ). "المناهج الدراسية والوعي الاجتماعي والسياسي للمرأة في مصر". التعليم ومستقبل المجتمع المدني. الاسكندرية. مركز الجزويت الثقافي.

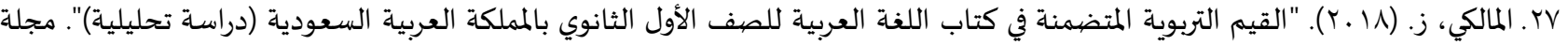

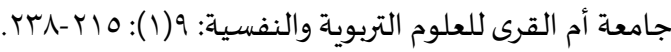

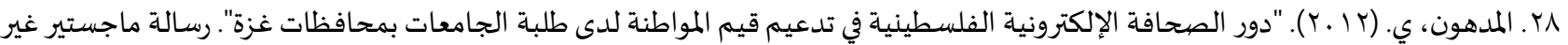
منشورة. جامعة الأزهر. غزة. فلسطين. 9. المنذري، ر. (عا . Y). "مستوى ممارسة معلمي اللغة العربية لأدوارهم في تنمية قيم المواطنة في نفوس الطلبة من وجهة نظر الطلبة أنفسهم

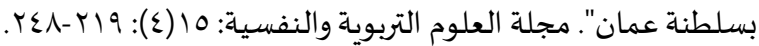

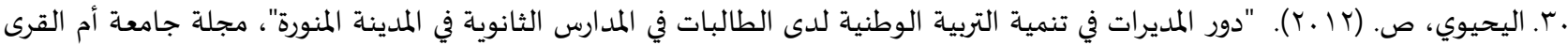

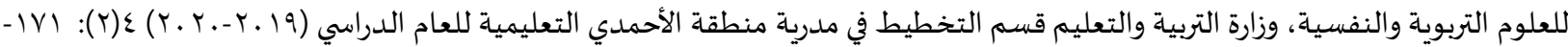
. TY.

(ب. يوسف، ن، القصبي، ر، وجورج، ج، ومرجان، ر. (ع) .ب). "تنمية قيم المواطنة لطلاب التعليم الثانوي في ضوء التحولات السياسية المعاصرة

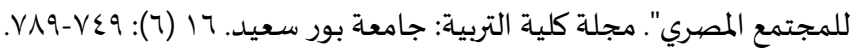

\section{ثانياً: المراجع الأجنبية:}

[1] Bassel, A. (2012). "Teaching for Citizenship in Lebanon: Teachers Talk about the Civics Classroom”. Teaching and Teacher Education, An International Journal of Research and Studies. 28(3): 470-480, https://doi.org/10.1016/j.tate.2011.12.002.

[2] Ford, J. (2011). "Political Socialization and Citizenship Education for Queer Youth". Unpublished PhD Thesis, Emory University. Georgia State, USA.

[3] Gwen, W. (2008) "The Meaning of Citizenship to Young Adults in the Post-communist Czech Republic". Unpublished PhD. Thesis. University of Minnesota. Minnesota State. USA.

[4] Humphreys, M. (2011). "Anew Generation of leaders for Eastern Europe: Values and attitudes for active citizenship". Christian Higher Education. 10(3-4): 215-236, https://doi.org/10.1080/15363759.2011.576209. 
[5] Iftikhar, A. (2006). "Teaching Government in Social Studies: Political Scientist's Contributions to Citizenship Education". Social Studies, 97 (1): 8-15, https://doi.org/10.3200/tsss.97.1.8-15.

[6] Koutselini, M. (2008). "Citizenship Education in Context: Student Teacher Perceptions of Citizenship in Cyprus", Intercultural Education. 19(2): 163-175, https://doi.org/10.1080/14675980801889690.

[7] Martin, T \& Yap, P. (2011). “Civic. Disparities: Exploring Student's Perceptions of citizenship within sing a pore's Academic Tracks". Theory and research in Social Education. 39 (2): 203-237, https://doi.org/10.1080/00933104.2011.10473453.

[8] Rapoprt , A. (2009). "A Forgotten Concept: Global Citizenship Education and State Social Studies Standards". Journal of Social Studies Research. 33 (1): 91-112.

[9] Udoukpong, B., \& Okon, C. (2012). "Educators Predisposition to Conceptual Perspectives in Achieving Citizenship Education Goal of Social Studies". International Journal of Business and Social Science. 3 (5): 222-229.

[10] Williams, randy pruce. (2002). Alberta social studies textbooks and human rights education DAI, 40(1) 30. UMINO. AACMG60403.

[11] Yilmaz, K \& Tasdan, M. (2009). "Organizational Citizenship and Organizational Justice in Turkish Primary Schools". Journal of Educational Administration. 47(1): 108-126, https://doi.org/10.1108/09578230910928106.

[12] Yusuf, A., Agbonna, S., Jekayinfa, A. \& Saliu, A. (2011). "Effects of Citizenship Education Component of Social Studies on Civic Literacy and Attachment of Upper Basic Students in Ilorin Metropolis Nigeria". African Journal of Political Science and International Relations. 5 (9): 61-66. 
المجلة الدولية للدراسـات التربوية والنفسية

International Journal of Educational \& Psychological Studies (EPS)

Journal Homepage: https://www.refaad.com/views/EPSR/Home.aspx

www.refaad.com

ISSN: 2520-4149 (Online) 2520-4130 (Print)

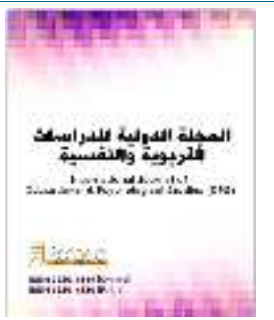

\title{
The role of social studies teachers in developing values of citizenship among secondary school students in Ahmadi governorate in the state of Kuwait from the view point of the students
}

\author{
Mallouh Baji Alkhrisha \\ malkhrisha1@yahoo.com \\ Ali Hadhram Al Hajri \\ Ministry of Education, Department of Social Studies, Kuwait \\ alialhajry1992@gmail.com
}

Professor in the Department of Educational Foundations and Administration, Mutah University, Jordan

Received Date : $11 / 2 / 2020$

Accepted Date : $17 / 3 / 2020$

DOI : https://doi.org/DOI:10.31559/EPS2020.8.2.8

\begin{abstract}
The study aimed at identifying the role of social studies teachers in developing values of citizenship among secondary school students in Ahmadi governorate in the State of Kuwait from the view point of the students. The sample of the study was consisted of (546) male and female Students whom were selected in a random stratified procedure. To achieve the objectives of the study, a questionnaire consisted of (38) items was developed and divided into four dimensions: (belonging and loyalty, political awareness, social work, tolerance and respect for the other).The study found that the degree of approval of the role of social studies teachers in the development of citizenship values among secondary school students in Ahmadi Governorate at Kuwait from the point of view of students was high. The results indicated that there were statistically significant differences at $(\alpha \leq 0.05)$ in Students' responses on the role of social studies teachers in the development of citizenship values among secondary school students attributed the variable of gender in favor of females, grade in favor of higher grade, and nationality in favor of Kuwaitis. Also, there were no significant statistical differences that were attributed to specialization variable. In light of the results, the researchers recommended: The need for teachers to train students to take responsibility through assigning duties, and involve them, especially students from nonKuwaiti nationalities in all activities and events that promote the values of citizenship.
\end{abstract}

Keywords: Social studies Teachers; Values of Citizenship; Students; Kuwait.

\section{References:}

[1] Al'dwan, Z, Bny Mstfa, F. (2015). "Athr Brnamj Tdryby Fy Tnmyh Mbad' Almwatnh Al'almyh Lda M'lmy Altarykh Fy Alardn". Mjlt Drasat Al'lwm Altrbwyh: 42 (1): 127-138.

[2] Al'qyl, ', Alhyary, H. (2014). "Dwr Aljam'at Alardnyh Fy Td'ym Qym Almwatnh". Almjlh Alardnyh Fy Al'lwm Altrbwyh: 10(4): 517-529.

[3] Al'tyby, H. (2016). "Dwr Mwjhy Altrbyh Alfnyh Fy T'zyz Qym Almwatnh Mn Wjht Nzr Alm'lmyn Fy Almrhlh Alabtda'yh Fy Dwlh Alkwyt". Rsalt Majstyr Ghyr Mnshwrh. Jam't Al Albyt. Almfrq. Alardn.

[4] Al'wamrh, ', Alzbwn, M. (2014). "Dwr Aljam'at Alardnyh Alrsmyh Fy T'zyz Trbyt Almwatnh W'laqtha Btnmyh Alastqlalyh Aldatyh Lda Tlbh Alyat Al'lwm Altrbwyh Mn Wjht Nzrhm". Mjlt Jam't Alnjah Llabhath (Al'lwm Alensanyh): 28(1): 187218.

[5] Abw Al'ynyn,'., Wwyh, M., Wbrkat, H. (2003). Alaswl Alflsfyh Lltrbyh, Qra'at Wdrasat. T1. Alardn. Dar Alfkr Lltba'h Waltwzy' Walnshr. S: 236-237.

[6] Bdarnh, M., Walmwmny, H, Wlbabnh,A., Wal'qyl, S. (2017). "Qym Altsamh Lda Talbat Klyt Arbd Aljam'yh W'laqtha Baldrjh Al'lmyh Waltqdyr Alakadymy". Drasat. Al'lwm Altrbwyh: 44(4): 209-224.

[7] Bdwy, A. (1982). M'jm Mstlhat Al'elwm Alajtma'yh. Byrwt: Mktbt Lbnan. S 62. 
[8] Brahmh, N. (2008). "Ttwyr Mnhaj Altrbyh Alwtnyh Walmdnyh Fy Dw' Khsa's Almwatnh Alsalhh Wqyas Athrh Fy Aktsab Mfahym Almwatnh Walatjahat Nhwha Lda TlbT Almrhlh Alasasyh Al'lya Fy Alardn". Atrwht Dktwrah Ghyr Mnshwrh. Jam't Alyrmwk. Arbd. Alardn.

[9] Bw Tbal, S., Wyahy, S. (2016). "Dwr Almdrsh Fy Tnmyh Qym Almwatnh Lda Almt'lmyn: Mrhlt Alt'lym Almtwst Walthanwy Nmwdjaan". Mjlt Al'lwm Alensanyh Walajtma'yh: 23 (3): 91-103.

[10] Ebrahym, Sh, Webrahym, N. (2001). "Ttwyr Mnahj Alt'lym Ltnmyh Almwatnh Fy Alalfyh Althalthh Lda Altlamyd Balmrhlh Althanwyh: Drash Tjrybyh". Almrkz Alqwmy Llbhwth Altrbwyh Waltnmyh. Alqahrh.

[11] Frj, A. (2001). "Almnahj Aldrasyh Walw'y Alajtma'y Walsyasy Llmrah Fy Msr". Alt'lym Wmstqbl Almjtm' Almdny. Alaskndryh. Mrkz Aljzwyt Althqafy.

[12] Alghafr, H, Als'ydy, H,Alhamdy, M. (2015). "Drjt Mmarsh M'lmy Altrbyh Aleslamyh Waldrasat Alajtma'yh Qym Almwatnh Fy Altfa'l Alsfy Mn Wjht Nzr Almshrfyn Altrbwyyn Fy Sltnt 'uman". Mjlt Tnmyt Almward Albshryh: 11: 228-264.

[13] Alghrybyh, Z. (2015). "Astratyjyh Lt'zyz Altrbyh Mn Ajl Almwatnh Fy Almdrsh Alhdythh". Mjlt Tnmyh Almward Albshryh: 11 (12): 6-24.

[14] Alhfzy, '. (2005). "Dwr Altrbyh Alwtnyh Fy Tnmyt Almwatnh Fy Almjtm' Als'wdy, Rsalt Majstyr Ghyr Mnshwrh". Altrbyh Aleslamyh Walmqarnh. Jam't Am Alqra. Mkh Almkrmh. Almmlkh Al'rbyh Als'wdyh.

[15] Alhrby, Q, Wswylm, M. (2017). "Tnmyh Almwatnh Lda Tlbt Aljam'at Als'wdyh". Mjlt Klyt Altrbyh: Jam't Alazhr. 176 (12): 13-54.

[16] Hsam, M., W M'bd, F. (2003). "Dwr Alm'ssat Altrbwyh Fy Mwajht Zahrt Al'nf Altlaby Fy Dw' Althdyat Alm'asrh". Alm'etmr Al'lmy Alsnwy Althany R'a Mstqblyh Lttwyr Alt'lym Qbl Aljam'y Fy Dw' Althdyat Al'easrh Fy Alftrh 21-22 Hzyran, Jam'eh 'yn Shms Alqahrh.

[17] Abw Hshysh, Bsam Mhmd. (2010). "Dwr Klyat Altrbyh Fy Tnmyh Qym Almwatnh Lda Altlbh Alm'lmyn Bmhafzat Ghzh", Mjlh Jam't Alaqsa (Slslh Al'lwm Alensanyh): 14(1): 250-279.

[18] Khdr, Fkhry Rshyd. (2011). "Athr Astkhdam Alqdaya Aljdlyh Fy Altdrys 'la Thsyl Tlbt Alsf Alsab' Alasasy Fy Madt Altrbyh Alwtnyh Walmdnyh". Almjlh Aldwlyh Llabhath Altrbwyh: 30: 1-25.

[19] Alkhza'lh, Ahmd M. (2018). "Drjt Mmarsh Altlbh Aldarsyn Lmadh Altrbyh Alwtnyh Fy Jam't Al Albyt Llqym Alwtnyh Mn Wjht Nzrhm Fy Alardn". Mjlt Jam't Alqds Almftwhh Llabhath Waldrasat Altrbwyh Walnfsyh: 8(24):84-93.

[20] Almalky, Z. (2018). "Alqym Altrbwyh Almtdmnh Fy Ktab Allghh Al'erbyh Llsf Alawl Althanwy Balmmlkh Al'erbyh Als'wdyh (Drash Thlylyh)". Mjlt Jam't Am Alqra Ll'lwm Altrbwyh Walnfsyh: 9(1): 215-238.

[21] Almdhwn, Y. (2012). "Dwr Alshafh Alelktrwnyh Alflstynyh Fy Td'ym Qym Almwatnh Lda Tlbt Aljam'at Bmhafzat Ghzh". Rsalt Majstyr Ghyr Mnshwrh. Jam't Alazhr. Ghzh. Flstyn.

[22] Almndry, R. (2014). "Mstwa Mmarst M'lmy Allghh Al'rbyh Ladwarhm Fy Tnmyt Qym Almwatnh Fy Nfws Altlbh Mn Wjht Nzr Altlbh Anfshm Bsltnh 'man". Mjlt Al'lwm Altrbwyh Walnfsyh: 15(4): 219-248.

[23] Nbyh, N. (2008). Mbda Almwatnh Byn Aljdl Walttbyq. Alaskndryh: Mrkz Alaskndryh Llktab. S 6-7.

[24] Rmdan, ', Wywsf, A. (2014). "Mfahym Almwatnh Fy Ktab Aldrasat Alajtma'yh Llsf Alkhams Alasasy Wdrjt Esham Alm'lmyn Fy Tnmytha". Mjlt Jam't Alb'th: 36 (5): 127-155.

[25] Alslym, B. (2015). "Alqym Altrbwyh Almtdmnh Balanashyd Alwardh Fy Ktb Lghtna Al'rbyh Lsfwf Almrhlh Alasasyh Alawla Fy Alardn". Mjlt Drasat Al'lwm Altrbwyh: 42(2), 601-617.

[26] Abw Snynh, '., Wghanm, B. (2011). "Hqwq Almwatnh Wwajbatha Kma Yraha M'lmw Aldrasat Alajtma'yh Fy Mdars Wkalh Alghwth Aldwlyh Fy Alardn". Mjlt Jam't Alaqsa (Slslh Al'lwm Alensanyh): 15(2): 1-31.

[27] Srwr, F, Al'zam, M. (2012). "Dwr Mnahj Altrbyh Aleslamyh Almtwrh Fy Tnmyt Qym Almwatnh Alsalhh Lda Tlab Almrhlh Alasasyh Al'lya Mn Wjht Nzr Alm'lmyn Fy Trbyt Arbd Althalthh", Drasat Al'lwm Altrbwyh. 39(2): 487-503.

[28] Th, A, 'bd Alhkym, F. (2013). Trbyt Almwatnh Byn Alnzryh Walttbyq. Mktbt Alanjlw Almsryh. Alqahrh.

[29] Alyhywy, S. (2012). "Dwr Almdyrat Fy Tnmyt Altrbyh Alwtnyh Lda Altalbat Fy Almdars Althanwyh Fy Almdynh Almnwrh", Mjlt Jam't Am Alqra Ll'lwm Altrbwyh Walnfsyh, Wzart Altrbyh Walt'lym Qsm Altkhtyt Fy Mdryt Mntqh Alahmdy Alt'lymyh Ll'am Aldrasy (2019-2020) 4(2): 171-220.

[30] Ywsf, N, Alqsby, R, Wjwrj, J, Wmrjan, R. (2014). "Tnmyt Qym Almwatnh Ltlab Alt'lym Althanwy Fy Dw' Althwlat Alsyasyh Alm'asrh Llmjtm' Almsry". Mjlt Klyt Altrbyh: Jam't Bwr S'yd. 16 (6): 749-789.

[31] Zhaj, H. (2017). "Dwr Alastad Fy Tnmyh Qym Almwatnh Lda Tlamyd Alt'lym Almtwst". Rsalt Majstyr Ghyr Mnshwrh. Jam't Zyan 'ashwr Aljlfh. Aljza'r. 